\title{
Quasi-E-Bayesian criteria versus quasi-Bayesian, quasi-hierarchical Bayesian and quasi-empirical Bayesian methods for estimating the scale parameter of the Erlang distribution
}

\author{
Hesham Mohamed Reyad ${ }^{1,2 *}$, Adil Mousa Younis ${ }^{1,2}$, Amal Alsir Alkhedir ${ }^{2}$ \\ ${ }^{1}$ College of Business and Economics, Qassim University, Kingdom of Saudi Arabia \\ ${ }^{2}$ Faculty of Science, Sudan University of Science and Technology, Sudan \\ *Corresponding author E-mail:hesham_reyad@yahoo.com
}

\begin{abstract}
This paper proposes a new modification for the E-Bayesian method of estimation to introduce a new technique namely Quasi E-Bayesian method (or briefly QE-Bayesian). The suggested criteria built in replacing the likelihood function by the quasi likelihood function in the E-Bayesian technique. This study is devoted to evaluate the performance of the new method versus the quasi-Bayesian, quasihierarchical Bayesian and quasi-empirical Bayesian approaches in estimating the scale parameter of the Erlang distribution. All estimators are obtained under symmetric loss function [squared error loss (SELF))] and four different asymmetric loss functions [Precautionary loss function (PLF), entropy loss function (ELF), Degroot loss function (DLF) and quadratic loss function (QLF)]. The properties of the QE-Bayesian estimates are introduced and the relations between the QE-Bayes and quasi-hierarchical Bayes estimates are discussed. Comparisons among all estimators are performed in terms of mean square error (MSE) via Monte Carlo simulation.
\end{abstract}

Keywords: Erlang Distribution; Quasi-Bayes Estimates; Quasi-E-Bayeses Estimates; Quasi-Empirical Bayes Estimates; Quasi-Hierarchical Bayes Estimates.

\section{Introduction}

The Erlang distribution has many applications because of its relation to the exponential and gamma distributions. Historically it was first introduced by Erlang [1] to be the distribution of waiting time and message length in telephone traffic. If the durations of individuals calls are obey exponential distribution, then the duration of a succession of calls has an Erlang distribution. The Erlang distribution is the sum of exponential variates and if its shape parameter becomes 2, it transformed to be chi-square distribution with $2 \mathrm{k}$ degrees of freedom. Also, the Erlang distribution is a gamma variate with an integer shape parameter. The probability density function (pdf) of the Erlang distribution is

$$
\mathrm{f}(\mathrm{x} ; \mathrm{k}, \theta)=\frac{\mathrm{x}^{\mathrm{k}-1} \mathrm{e}^{\frac{-\mathrm{x}}{\theta}}}{\theta^{\mathrm{k}} \Gamma(\mathrm{k})}, \quad \mathrm{x}>0, \lambda, \theta>0, \mathrm{k}=1,2,3, \ldots
$$

Where $\theta$ and $\mathrm{k}$ are the scale and shape parameter respectively. Several authors have studied the Erlang distribution; for examples, Harischandra and Rao [2] investigated the problems with classical inferences for the Erlangian queue. Bhattacharyya and Singh [3] obtained a Bayes estimator for the Erlangian queue based on two prior distributions. Fang [4] introduced a study of the hyperErlang distribution model and its applications in wireless networks and mobile computing systems. Abdelkader [5] obtained the moments of order statistics from non-identically distributed Erlang distribution. Suri et al [6] applied the Erlang distribution to design a simulator for time estimation of project management process. Haq and Dey [7] obtained the Bayesian estimates of parameters for the Erlang distribution based on various independent informative priors. Bakoban [8] derived the maximum likelihood and bayes estimates for the scale parameter, reliability and cumulative hazard functions under LINEX and entropy loss functions. Khan and Jan [9] obtained the Bayes parameters estimation based on different generalized truncated prior distributions.

The method of quasi-likelihood was first proposed by Wedderbum [10] for estimating the parameters in generalized linear model if only there exist a specified relationship between mean and variance of each observation. Wedderbum [10] defined the quasilikelihood function for an observation $\mathrm{x}$ with mean $\mu$ and variance $V(\mu)$ as follows:

$\frac{\partial \mathrm{Q}(\mathrm{x} ; \mu)}{\partial \mu}=\frac{\mathrm{x}-\mu}{\mathrm{V}(\mu)}$

Or equivalent by

$$
Q(x ; \mu)=\int_{\mu} \frac{x-\mu}{V(\mu)} d \mu+\text { function of } X
$$

Where $\mu=\mathrm{E}(\mathrm{x}), v(\mu)=\operatorname{var}(\mathrm{x})$. The variance assumption is generalized to $\operatorname{var}(\mathrm{x})=\phi \mathrm{v}(\mu)$, where the variance function $\mathrm{v}($.$) is as-$ sumed to be known and the parameter $\phi$ may be unknown. Wedderbum [10] also concluded that if the observations are distributed one parameter exponential, then the quasi-likelihood has the same properties of the log-likelihood function and so each of each of them has the similar asymptotic efficiency.

The E-Bayesian estimation is a new criteria of estimation was first proposed by Han [11].Han [12] obtained the E-Bayes and hierar- 
chical Bayes estimates for reliability parameter of the exponential distribution based on type-I censored data and by considering the quadratic loss function. Yin and Liu [13] constructed the EBayesian estimation and hierarchical Bayesian estimation techniques for estimating the unknown reliability parameter of the geometric distribution by considering the scaled squared loss function in complete samples. The minimum risk equivariant and EBayes estimates for the unknown parameter of the Burr-XII distribution based on entropy loss function in complete samples were obtained by Wei et al [14]. Jaheen and Okasha [15] derived the Bayesian and E-Bayesian estimators for the parameters and reliability function of the Burr-XII distribution based on type-II censoring and by considering the squared error loss and LINEX loss functions. Cai et al [16] used the E-Bayesian estimation method for forecasting of security investment. Okasha [17] applied the maximum likelihood, Bayesian and E-Bayesian approaches for estimating the unknown scale parameter, reliability and hazard functions of the Weibull distribution based on type-ii censoring and by considering the squared error loss function. Wu [18] proposed the Bayesian estimation and E-Bayesian estimation methods in a new integral interval for estimating the failure probability under zero-failure data and by considering the quadratic loss function. Azimi et al [19] obtained the Bayes and E-Bayes estimates for the parameter and reliability function of the generalized half Logistic distribution based on progressively type-II censored data and by considering the squared error loss and LINEX loss functions. Javadkani et al [20] constructed the Bayes, empirical Bayes and E-Bayes methods for estimating the unknown shape parameter and the reliability function of the two parameter bathtub-shaped lifetime distribution based on progressively first-failure-censoring and by considering the minimum expected loss and LINEX loss functions. Liu et al [21] obtained the E-Bayes and hierarchical estimates for the unknown parameter of the Rayleigh distribution based on q-symmetric entropy loss function in complete samples. Okasha [22] derived the Bayesian and the E-Bayesian estimates of the scale parameter, reliability and hazard functions of the Lomax distribution under on type-ii censoring and by considering the balanced squared error loss function. Reyad and Othman [23] obtained the Bayesian and E-Bayesian estimates for the shape parameter of the Gumbell type-II distribution based on type-ii censoring and by considering squared error, LINEX, Degroot, quadratic and minimum expected loss functions. Reyad and Othman [24] constructed the Bayes and E-Bayes approaches for estimating the unknown shape parameter of the Kumaraswamy distribution based on type-ii censored data and by considering squared error, LINEX, Degroot, quadratic. Reyad et al [25] obtained the Bayes, E-bayes, hierarchical Bayes and empirical Bayes estimates of the unknown shape parameter and hazard function of the Gompertz distribution based on type-II censoring and by considering squared error loss, quadratic loss entropy loss and LINEX functions.

The main object of this study is to suggested a new modification for the E-Bayes method of estimation to yield a new technique namely quasi-E-Bayes method (or briefly QE-Bayes). The new method is compared with other three different techniques; quasiBayes, quasi-hierarchical Bayes and quasi-empirical Bayes for estimating the scale parameter associated to the Erlang distribution. The resulting estimates are obtained based on symmetric and different asymmetric loss functions. The properties of the new method are discussed and the relations with the quasi-hierarchical Bayes estimates are also investigated. All outcomes obtained in this article showed that the proposed method is more efficient and easy to operate.

The remainder of this paper is organized as follow. In Section 2, the quasi-Bayes estimates of the parameter $\theta$ are derived under SELF, PLF, ELF, DLF and QLF. The QE-Bayes estimates are obtained of the parameter $\theta$ under SELF, PLF, ELF, DLF and QLF in Section 3. In Section 4, 5, the quasi-hierarchical Bayes and quasi-empirical Bayes estimates of the parameter $\theta$ are derived under SELF, PLF, ELF,DLF and QLF respectively. In Section 6, the properties of the QE-Bayes estimates are investigated and the relations among the QE-Bayes and quasi-hierarchical Bayes estimates are derived. In Section 7, a Monte Carlo simulation is performed to compare the performance of the resulting estimates. Some concluding remarks have been given in the last Section.

\section{The quasi-Bayesian estimation}

In this section, we will obtain the quasi-Bayes estimates of the scale parameter of the Erlang distribution by considering symmetric loss function [squared error loss (SELF))] and four different asymmetric loss functions [Precautionary loss function (PLF), entropy loss function (ELF), Degroot loss function (DLF) and quadratic loss function (QLF)]. The mean and variance of the Erlang distribution given in (1-1) is given by

$\mu=\mathrm{E}(\mathrm{x})=\theta \mathrm{k}, \quad \mathrm{v}(\mathrm{x})=\theta^{2} \mathrm{k}=\phi \mathrm{v}(\mu)$

Where

$\phi=\theta, \quad \mathrm{v}(\mu)=\mu$

Thus for a random sample of size $\mathrm{n}$, the quasi-likelihood function can be obtained for the Erlang distribution by using (1-2) and (1$3)$ in (1-1) to be

$$
\frac{\partial \mathrm{Q}(\mathrm{x} ; \mu)}{\partial \mu}=\frac{\sum_{i=1}^{\mathrm{n}} \mathrm{x}_{\mathrm{i}}-\mathrm{n} \mu}{\mu}
$$

Which gives

$$
\mathrm{Q}(\mathrm{x} ; \mu)=\sum_{\mathrm{i}=1}^{\mathrm{n}} \mathrm{x}_{\mathrm{i}} \ln \mu-\mathrm{n} \mu
$$

We can obtain the quasi-likelihood function as a function in $\theta$ and $\mathrm{k}$ by using (2-1) in (2-4) to be

$$
\mathrm{Q}(\mathrm{x} ; \theta, \mathrm{k})=\ln (\theta \mathrm{k})^{\sum_{i=1}^{\mathrm{n}} \mathrm{x}_{\mathrm{i}}}-\mathrm{n} \theta \mathrm{k}
$$

The natural exponential of the quasi-likelihood function is given by

$$
\exp [\mathrm{Q}(\mathrm{x} ; \theta, \mathrm{k})]=(\theta \mathrm{k}) \sum_{\mathrm{i}=1}^{\mathrm{n}} \mathrm{x}_{\mathrm{i}} \mathrm{e}^{-\mathrm{n \theta k}}
$$

Assuming $\mathrm{k}$ is known, then the quasi-likelihood function become

$\exp [\mathrm{Q}(\mathrm{x} ; \theta)] \propto \theta^{\mathrm{w}} \mathrm{e}^{-\mathrm{n} \theta \mathrm{k}}$

Where

$\mathrm{W}=\sum_{\mathrm{i}=1}^{\mathrm{n}} \mathrm{x}_{\mathrm{i}}$

We can use the exponential distribution as a conjugate prior distribution of $\theta$ with rate parameter a and its pdf given by

$$
\mathrm{g}(\theta \mid \mathrm{a})=\mathrm{a} \mathrm{e}^{-\mathrm{a} \theta}, \quad \quad \theta>0, \mathrm{a}>0
$$

In quasi-Bayesian estimation approach, the likelihood function is replaced by the natural exponential of the quasi-likelihood function. Combining (2-7) and (2-9), the quasi posterior distribution of $\theta$ can be obtained as

$$
\begin{aligned}
\mathrm{h}_{1}(\theta \mid \underline{\mathrm{x}}) & =\frac{\exp [\mathrm{Q}(\mathrm{x} ; \theta)] \mathrm{g}(\theta \mid \mathrm{a})}{\int_{0}^{\infty} \exp [\mathrm{Q}(\mathrm{x} ; \theta)] \mathrm{g}(\theta \mid \mathrm{a}) \mathrm{d} \theta} \\
& =\frac{(\mathrm{a}+\mathrm{nk})^{\mathrm{w}+1}}{\Gamma(\mathrm{w}+1)} \theta^{\mathrm{w}} \mathrm{e}^{-\theta(\mathrm{a} \text { +nk })}, \quad \theta>0, \mathrm{a}>0
\end{aligned}
$$


That mean, the quasi posterior distribution of $\theta$ obeys $\Gamma(\mathrm{w}+1, \mathrm{a}+\mathrm{nk})$.

\subsection{The quasi-Bayesian estimation under squared error} loss function (SELF)

A commonly used loss function is the square error loss function (SELF) introduced by Mood et al (26) as follows:

$$
\mathrm{L}_{1}(\hat{\theta}, \theta)=\mathrm{r}(\hat{\theta}-\theta)^{2}, \quad \mathrm{k}>0
$$

Where $\hat{\theta}$ is an estimator of $\theta$ and $r$ is the scale of the loss function. The scale $r$ is often taken equal to one which has no effect on the Bayes estimates. This loss function is symmetric in nature. i.e. it gives equal importance to both over and under estimation. The quasi-Bayes estimator of $\theta$ denoted by $\hat{\theta}_{\mathrm{oBs}}$ can be obtained as

$\hat{\theta}_{\mathrm{QBS}}=\mathrm{E}_{\pi}(\theta \mid \underline{\mathrm{x}})$

Where $\mathrm{E}_{\pi}$ indicated to the expectation of the quasi posterior distribution. We can derived $\hat{\theta}_{\mathrm{QBS}}$ by using (2-10) in (2-12) to be

$\hat{\theta}_{\mathrm{QBS}}=\frac{\mathrm{w}+1}{\mathrm{a}+\mathrm{nk}}$

\subsection{The quasi-Bayesian estimation under precautionary loss function (PLF)}

Nostrom [27] defined the precautionary loss function (PLF) as follows:

$\mathrm{L}_{2}(\hat{\theta}, \theta)=\frac{(\hat{\theta}-\theta)^{2}}{\hat{\theta}}$

The quasi-Bayes estimator of $\theta$ based on PLF denoted by $\hat{\theta}_{\text {Рвв }}$ can be obtained as

$$
\hat{\theta}_{\mathrm{QBP}}=\left[\mathrm{E}_{\pi}\left(\theta^{2} \mid \underline{\mathrm{x}}\right)\right]^{\frac{1}{2}}
$$

We can derived $\hat{\theta}_{\mathrm{OBP}}$ by using (2-10) in (2-15) to be

$\hat{\theta}_{\mathrm{QBP}}=\frac{\sqrt{(\mathrm{w}+1)(\mathrm{w}+2)}}{\mathrm{a}+\mathrm{nk}}$

\subsection{The quasi-Bayesian estimation under entropy loss function (ELF)}

Day et al [28] have discussed the entropy loss function (ELF) of the form

$\mathrm{L}_{3}(\hat{\theta}, \theta) \propto\left(\frac{\hat{\theta}}{\theta}\right)-\ln \left(\frac{\hat{\theta}}{\theta}\right)-1$

The quasi-Bayes estimator of $\theta$ relative to ELF denoted by $\hat{\theta}_{\mathrm{OB}}$ can be obtained as

$$
\hat{\theta}_{\mathrm{OBE}}=\left[\mathrm{E}_{\pi}\left(\theta^{-1} \mid \underline{\mathbf{x}}\right)\right]^{-1}
$$

We can obtain $\hat{\theta}_{\mathrm{QBE}}$ by using (2-10) in (2-18) to be

$$
\hat{\theta}_{\mathrm{QBE}}=\frac{\mathrm{w}}{\mathrm{a}+\mathrm{nk}}
$$

\subsection{The quasi-Bayesian estimation under Degroot loss} function (DLF)

The Degroot loss function (DLF) is defined by Degroot [29] to be

$$
\mathrm{L}_{4}(\hat{\theta}, \theta)=\left(\frac{\theta-\hat{\theta}}{\hat{\theta}}\right)
$$

The quasi-Bayes estimator relative to DLF denoted by $\hat{\theta}_{\text {Свв }}$ can be obtained as

$$
\hat{\theta}_{\mathrm{QBD}}=\frac{\mathrm{E}_{\pi}\left(\theta^{2} \mid \underline{\mathrm{x}}\right)}{\mathrm{E}_{\pi}(\theta \mid \underline{\mathbf{x}})}
$$

We can obtain $\hat{\theta}_{\text {वв }}$ by using (2-10) in (2-21) to be

$\hat{\theta}_{\mathrm{QBD}}=\frac{\mathrm{w}+2}{\mathrm{a}+\mathrm{nk}}$

\subsection{The quasi-Bayesian estimation under quadratic loss function (QLF)}

Bhuiyan et al [30] defined the quadratic loss function (QLF) as follows:

$$
\mathrm{L}_{5}(\hat{\theta}, \theta)=\left(\frac{\theta-\hat{\theta}}{\hat{\theta}}\right)
$$

The quasi-Bayes estimator of $\theta$ based on QLF denoted by $\hat{\theta}_{\text {Вве }}$ can be obtained as

$$
\hat{\theta}_{\text {Qве }}=\frac{\mathrm{E}_{\pi}\left(\theta^{-1} \mid \underline{\mathrm{x}}\right)}{\mathrm{E}_{\pi}\left(\theta^{-2} \mid \underline{\mathrm{x}}\right)}
$$

We can derived $\hat{\theta}_{\mathrm{ORQ}}$ by using (2-10) in (2-24) to be

$\hat{\theta}_{\text {вве }}=\frac{\mathrm{w}-1}{\mathrm{a}+\mathrm{nk}}$

\section{The quasi-E-Bayesian estimation}

In this section, we have derived the quasi-E-Bayes estimates for the scale parameter of the Erlang distribution by considering symmetric loss function [squared error loss (SELF))] and four different asymmetric loss functions [Precautionary loss function (PLF), entropy loss function (ELF), Degroot loss function (DLF) and quadratic loss function (QLF)]. Based on Han [30], the hyper parameter a must be choosing to guarantee that $\mathrm{g}(\theta \mid \mathrm{a})$ given in (2-9) is a decreasing function of $\theta$. The derivative of $g(\theta \mid a)$ with respect to $\theta$ is

$$
\frac{\operatorname{dg}(\theta \mid a)}{d \theta}=\left(-a^{2}\right) \exp [-a \theta]
$$

Note that $\mathrm{a}>0$ and $\theta>0$ leads to for any value of $0<\mathrm{a}<\infty$, imply to $\frac{\operatorname{dg}(\theta \mid a)}{d \theta}<0$, and therefore $g(\theta \mid a)$ is a decreasing function of $\theta$. Consequently, it is convention to choose the hyper parameter a under the restriction $0<\mathrm{a}<\mathrm{c}$, where $\mathrm{c}$ is a given upper bound ( $\mathrm{c}$ is a positive constant).

Definition: Let $\hat{\theta}(\mathrm{x})$ be continuous, if 
Then

$$
\hat{\theta}_{\mathrm{QEB}}=\int_{\Omega} \hat{\theta}_{\mathrm{QB}}(\mathrm{a}) \pi(\mathrm{a}) \mathrm{da}
$$

Is called the QE-Bayesian estimation (expected quasi-Bayesian estimation) of $\theta$, where $\Omega$ is the set of all possible value of a , $\hat{\theta}_{\mathrm{QB}}(\mathrm{a})$ is the quasi-Bayes estimation of $\theta$ with the hyper parameter a and $\pi(\mathrm{a})$ is the prior distribution corresponding to the hyper parameter a over $\Omega$.

\subsection{The QE-Bayesian estimation under squared error loss function (SELF)}

The QE-Bayesian estimates of $\theta$ are derived depending on three different distributions of the hyper parameter a . These distributions are used to study the impact of the different prior distributions on the QE-Bayesian estimation of $\theta$. The following distributions of a may be used:

$$
\begin{array}{ll}
\pi_{1}(\mathrm{a})=\frac{1}{\mathrm{c}}, & 0<\mathrm{a}<\mathrm{c} \\
\pi_{2}(\mathrm{a})=\frac{2 \mathrm{a}}{\mathrm{c}^{2}}, & 0<\mathrm{a}<\mathrm{c} \\
\pi_{3}(\mathrm{a})=\frac{2(\mathrm{c}-\mathrm{a})}{\mathrm{c}^{2}}, & 0<\mathrm{a}<\mathrm{c}
\end{array}
$$

We can obtain the QE-Bayesian estimate of $\theta$ relative to SELF based on $\pi_{1}(a)$ which is denoted as $\hat{\theta}_{\text {QEBSI }}$ by using (2-13) and (3-3) in (3-2) to be

$$
\hat{\theta}_{\text {QEBSL }}=\int_{0}^{c}\left(\frac{\mathrm{w}+1}{\mathrm{a}+\mathrm{nk}}\right)\left(\frac{1}{\mathrm{c}}\right) \mathrm{da}=\left(\frac{\mathrm{w}+1}{\mathrm{c}}\right) \ln \left[1+\frac{\mathrm{c}}{\mathrm{nk}}\right]
$$

Similarly, we can derive the QE-Bayesian estimates of $\theta$ relative to SELF based on $\pi_{2}(a)$ and $\pi_{3}$ (a) which are denoted as $\hat{\theta}_{\text {QEBS2}}, \hat{\theta}_{\text {QEBS3 }}$ by using (2-13), (3-4) in (3-2) and (2-13), (3-5) in (32) respectively to be

$$
\hat{\theta}_{\text {QвBS2 }}=\int_{0}^{c}\left(\frac{\mathrm{w}+1}{\mathrm{a}+\mathrm{nk}}\right)\left(\frac{2 \mathrm{a}}{\mathrm{c}^{2}}\right) \mathrm{da}=\left(\frac{2(\mathrm{w}+1)}{\mathrm{c}}\right)\left[1-\left(\frac{\mathrm{nk}}{\mathrm{c}}\right) \ln \left(1+\frac{\mathrm{c}}{\mathrm{nk}}\right)\right]
$$

And

$$
\begin{aligned}
\hat{\theta}_{\text {QEBS3 }} & =\int_{0}^{c}\left(\frac{\mathrm{w}+1}{\mathrm{a}+\mathrm{nk}}\right)\left(\frac{2(\mathrm{c}-\mathrm{a})}{\mathrm{c}^{2}}\right) \mathrm{da} \\
& =\left(\frac{2(\mathrm{w}+1)}{\mathrm{c}}\right)\left[\left(1+\frac{\mathrm{nk}}{\mathrm{c}}\right) \ln \left(1+\frac{\mathrm{c}}{\mathrm{nk}}\right)-1\right]
\end{aligned}
$$

\subsection{The QE-Bayesian estimation under precautionary loss function (PLF)}

We can obtain the QE-Bayesian estimate of $\theta$ relative to PLF based on $\pi_{1}$ (a) which is denoted as $\hat{\theta}_{\text {QЕBP }}$ by using (2-16) and (3-3) in (3-2) to be

$$
\begin{aligned}
\hat{\theta}_{\text {QEBPI }} & =\int_{0}^{c}\left(\frac{\sqrt{(\mathrm{w}+1)(\mathrm{w}+2)}}{\mathrm{a}+\mathrm{nk}}\right)\left(\frac{1}{\mathrm{c}}\right) \mathrm{da} \\
& =\left(\frac{\sqrt{(\mathrm{w}+1)(\mathrm{w}+2)}}{\mathrm{c}}\right) \ln \left[1+\frac{\mathrm{c}}{\mathrm{nk}}\right]
\end{aligned}
$$

Also, we can derive the QE-Bayesian estimates of $\theta$ relative to PLF based on $\pi_{2}$ (a) and $\pi_{3}$ (a) which are denoted as $\hat{\theta}_{\text {QЕBP }}, \hat{\theta}_{\text {QRBP3 }}$ by using (2-16), (3-4) in (3-2) and (2-16), (3-5) in (3-2) respectively to be

$$
\begin{aligned}
\hat{\theta}_{\mathrm{QEBP} 2} & =\int_{0}^{c}\left(\frac{\sqrt{(\mathrm{w}+1)(\mathrm{w}+2)}}{\mathrm{a}+\mathrm{nk}}\right)\left(\frac{2 \mathrm{a}}{\mathrm{c}^{2}}\right) \mathrm{da} \\
& =\left(\frac{2 \sqrt{(\mathrm{w}+1)(\mathrm{w}+2)}}{\mathrm{c}}\right)\left[1-\left(\frac{\mathrm{nk}}{\mathrm{c}}\right) \ln \left(1+\frac{\mathrm{c}}{\mathrm{nk}}\right)\right]
\end{aligned}
$$

And

$$
\begin{aligned}
\hat{\theta}_{\text {QEBP3 }} & =\int_{0}^{c}\left(\frac{\sqrt{(\mathrm{w}+1)(\mathrm{w}+2)}}{\mathrm{a}+\mathrm{nk}}\right)\left(\frac{2(\mathrm{c}-\mathrm{a})}{\mathrm{c}^{2}}\right) \mathrm{da} \\
& =\left(\frac{2 \sqrt{(\mathrm{w}+1)(\mathrm{w}+2)}}{\mathrm{c}}\right)\left[\left(1+\frac{\mathrm{nk}}{\mathrm{c}}\right) \ln \left(1+\frac{\mathrm{c}}{\mathrm{nk}}\right)-1\right]
\end{aligned}
$$

\subsection{The QE-Bayesian estimation under entropy loss function (ELF)}

We can get the QE-Bayesian estimate of $\theta$ relative to ELF based on $\pi_{1}$ (a) which is denoted as $\hat{\theta}_{\text {QEBEI }}$ by using (2-19) and (3-3) in (3-2) to be

$\hat{\theta}_{\text {QEBEI }}=\int_{0}^{c}\left(\frac{\mathrm{w}}{\mathrm{a}+\mathrm{nk}}\right)\left(\frac{1}{\mathrm{c}}\right) \mathrm{da}=\left(\frac{\mathrm{w}}{\mathrm{c}}\right) \ln \left[1+\frac{\mathrm{c}}{\mathrm{nk}}\right]$

Also, we can derive the QE-Bayesian estimates of $\theta$ relative to ELF based on $\pi_{2}$ (a) and $\pi_{3}$ (a) which are denoted as $\hat{\theta}_{\text {огве }}, \hat{\theta}_{\text {огев }}$ by using (2-19), (3-4) in (3-2) and (2-19), (3-5) in (3-2) respectively to be

$$
\begin{aligned}
\hat{\theta}_{\text {QЕBE2 }} & =\int_{0}^{c}\left(\frac{\mathrm{w}}{\mathrm{a}+\mathrm{nk}}\right)\left(\frac{2 \mathrm{a}}{\mathrm{c}^{2}}\right) \mathrm{da} \\
& =\left(\frac{2 \mathrm{w}}{\mathrm{c}}\right)\left[1-\left(\frac{\mathrm{nk}}{\mathrm{c}}\right) \ln \left(1+\frac{\mathrm{c}}{\mathrm{nk}}\right)\right]
\end{aligned}
$$

And

$\hat{\theta}_{\mathrm{QEBE3} 3}=\int_{0}^{\mathrm{c}}\left(\frac{\mathrm{w}}{\mathrm{a}+\mathrm{nk}}\right)\left(\frac{2(\mathrm{c}-\mathrm{a})}{\mathrm{c}^{2}}\right) \mathrm{da}=\left(\frac{2 \mathrm{w}}{\mathrm{c}}\right)\left[\left(1+\frac{\mathrm{nk}}{\mathrm{c}}\right) \ln \left(1+\frac{\mathrm{c}}{\mathrm{nk}}\right)-1\right]$

\subsection{The QE-Bayesian estimation under Degroot loss function (DLF)}

We can get the QE-Bayesian estimate of $\theta$ relative to DLF based on $\pi_{1}$ (a) which is denoted as $\hat{\theta}_{\text {QевD }}$ by using (2-22) and (3-3) in (3-2) to be

$$
\hat{\theta}_{\text {QЕEЕI }}=\int_{0}^{c}\left(\frac{\mathrm{w}+2}{\mathrm{a}+\mathrm{nk}}\right)\left(\frac{1}{\mathrm{c}}\right) \mathrm{da}=\left(\frac{\mathrm{w}+2}{\mathrm{c}}\right) \ln \left[1+\frac{\mathrm{c}}{\mathrm{nk}}\right]
$$

Also, we can derive the QE-Bayesian estimates of $\theta$ relative to DLF based on $\pi_{2}$ (a) and $\pi_{3}$ (a) which are denoted as $\hat{\theta}_{\text {OЕВD }}, \hat{\theta}_{\text {OЕВ } 3}$ by using (2-22), (3-4) in (3-2) and (2-22), (3-5) in (3-2) respectively to be

$$
\begin{aligned}
\hat{\theta}_{\mathrm{QEBD} 2} & =\int_{0}^{c}\left(\frac{\mathrm{w}+2}{\mathrm{a}+\mathrm{nk}}\right)\left(\frac{2 \mathrm{a}}{\mathrm{c}^{2}}\right) \mathrm{da} \\
& =\left(\frac{2(\mathrm{w}+2)}{\mathrm{c}}\right)\left[1-\left(\frac{\mathrm{nk}}{\mathrm{c}}\right) \ln \left(1+\frac{\mathrm{c}}{\mathrm{nk}}\right)\right]
\end{aligned}
$$


And

$$
\begin{aligned}
\hat{\theta}_{\text {QEBD } 3} & =\int_{0}^{c}\left(\frac{\mathrm{w}+2}{\mathrm{a}+\mathrm{nk}}\right)\left(\frac{2(\mathrm{c}-\mathrm{a})}{\mathrm{c}^{2}}\right) \mathrm{da} \\
& =\left(\frac{2(\mathrm{w}+2)}{\mathrm{c}}\right)\left[\left(1+\frac{\mathrm{nk}}{\mathrm{c}}\right) \ln \left(1+\frac{\mathrm{c}}{\mathrm{nk}}\right)-1\right]
\end{aligned}
$$

\subsection{The QE-Bayesian estimation under quadratic loss function (QLF)}

We can get the QE-Bayesian estimate of $\theta$ relative to QLF based on $\pi_{1}$ (a) which is denoted as $\hat{\theta}_{\text {QЕвQ1 }}$ by using (2-25) and (3-3) in (3-2) to be

$$
\hat{\theta}_{\text {QвBQ1 }}=\int_{0}^{c}\left(\frac{\mathrm{w}-1}{\mathrm{a}+\mathrm{nk}}\right)\left(\frac{1}{\mathrm{c}}\right) \mathrm{da}=\left(\frac{\mathrm{w}-1}{\mathrm{c}}\right) \ln \left[1+\frac{\mathrm{c}}{\mathrm{nk}}\right]
$$

Also, we can derive the QE-Bayesian estimates of $\theta$ relative to DLF based on $\pi_{2}$ (a) and $\pi_{3}$ (a) which are denoted as $\hat{\theta}_{\text {Qвве2 }}, \hat{\theta}_{\text {РЕвㅇ } 3}$ by using (2-25), (3-4) in (3-2) and (2-25), (3-5) in (3-2) respectively to

$$
\begin{aligned}
\hat{\theta}_{\text {QЕвQ2 }} & =\int_{0}^{c}\left(\frac{\mathrm{w}-1}{\mathrm{a}+\mathrm{nk}}\right)\left(\frac{2 \mathrm{a}}{\mathrm{c}^{2}}\right) \mathrm{da} \\
& =\left(\frac{2(\mathrm{w}-1)}{\mathrm{c}}\right)\left[1-\left(\frac{\mathrm{nk}}{\mathrm{c}}\right) \ln \left(1+\frac{\mathrm{c}}{\mathrm{nk}}\right)\right]
\end{aligned}
$$

And

$$
\begin{aligned}
\hat{\theta}_{\text {QЕBO3 }} & =\int_{0}^{c}\left(\frac{\mathrm{w}+2}{\mathrm{a}+\mathrm{nk}}\right)\left(\frac{2(\mathrm{c}-\mathrm{a})}{\mathrm{c}^{2}}\right) \mathrm{da} \\
& =\left(\frac{2(\mathrm{w}-1)}{\mathrm{c}}\right)\left[\left(1+\frac{\mathrm{nk}}{\mathrm{c}}\right) \ln \left(1+\frac{\mathrm{c}}{\mathrm{nk}}\right)-1\right]
\end{aligned}
$$

\section{Quasi-hierarchical Bayesian estimation}

In this section, we have obtained the quasi-hierarchical Bayes estimates for the scale parameter of the Erlang distribution by considering symmetric loss function [squared error loss (SELF))] and four different asymmetric loss functions [Precautionary loss function (PLF), entropy loss function (ELF), Degroot loss function (DLF) and quadratic loss function (QLF)]. According to Lindley and Smith [32], if a is a hyper parameter in $\theta$, the prior density function of $\theta$ is $\operatorname{g}(\theta \mid \mathrm{a})$ given in (2-9) and the prior density functions of the hyper parameter a is given in (3-3), (3-4) and (3$5)$, then the corresponding quasi hierarchical prior density functions of $\theta$ are given as the following:

$$
\begin{aligned}
& \pi_{4}(\theta)=\int_{0}^{c}\left(\mathrm{a}^{-a \theta}\right)\left(\frac{1}{c}\right) \mathrm{da}=\left(\frac{1}{\mathrm{c}}\right) \int_{0}^{c} \mathrm{ae}^{-\mathrm{a} a} \mathrm{da}, \\
& \pi_{5}(\theta)=\int_{0}^{c}\left(\mathrm{a}^{-\mathrm{aa} \theta}\right)\left(\frac{2 \mathrm{a}}{\mathrm{c}^{2}}\right) \mathrm{da}=\left(\frac{2}{\mathrm{c}^{2}}\right) \int_{0}^{c} \mathrm{a}^{2} \mathrm{e}^{-\mathrm{a \theta}} \mathrm{da},
\end{aligned}
$$

And

$$
\pi_{6}(\theta)=\int_{0}^{c}\left(\mathrm{a} \mathrm{e}^{-\mathrm{a} \theta}\right)\left(\frac{2(\mathrm{c}-\mathrm{a})}{\mathrm{c}^{2}}\right) \mathrm{da}=\left(\frac{2}{\mathrm{c}^{2}}\right) \int_{0}^{c} \mathrm{a}(\mathrm{c}-\mathrm{a}) \mathrm{e}^{-\mathrm{a} \theta} \mathrm{da},
$$

The associated quasi hierarchical posterior density functions of $\theta$ can be derived by combining (2-7), (4-1), (4-2) and (4-3) to be

$$
\begin{aligned}
\mathrm{h}_{2}(\theta \mid \underline{\mathrm{x}}) & =\frac{\exp [\mathrm{Q}(\mathrm{x} ; \theta)] \pi_{4}(\theta)}{\int_{0}^{\infty} \exp [\mathrm{Q}(\mathrm{x} ; \theta)] \pi_{4}(\theta) \mathrm{d} \theta} \\
& =\frac{\int_{0}^{c} \mathrm{a} \theta^{\mathrm{w}} \mathrm{e}^{-\theta(\mathrm{a}+\mathrm{nk})} \mathrm{da}}{\Gamma(\mathrm{w}+1) \int_{0}^{c} \mathrm{a}[\mathrm{a}+\mathrm{nk}]^{-(\mathrm{w}+1)} \mathrm{da}}, \\
\mathrm{h}_{3}(\theta \mid \underline{\mathrm{x}}) & =\frac{\exp [\mathrm{Q}(\mathrm{x} ; \theta)] \pi_{5}(\theta)}{\int_{0}^{\infty} \exp [\mathrm{Q}(\mathrm{x} ; \theta)] \pi_{5}(\theta) \mathrm{d} \theta} \\
& =\frac{\int_{0}^{c} \mathrm{a}^{2} \theta^{\mathrm{w}} \mathrm{e}^{-\theta(a+n)} \mathrm{da}}{\Gamma(\mathrm{w}+1) \int_{0}^{c} \mathrm{a}^{2}[\mathrm{a}+\mathrm{nk}]^{-(\mathrm{w}+1)} \mathrm{da}},
\end{aligned}
$$

And

$$
\begin{aligned}
\mathrm{h}_{4}(\theta \mid \underline{\mathbf{x}}) & =\frac{\exp [\mathrm{Q}(\mathrm{x} ; \theta)] \pi_{6}(\theta)}{\int_{0}^{\infty} \exp [\mathrm{Q}(\mathrm{x} ; \theta)] \pi_{6}(\theta) \mathrm{d} \theta} \\
& =\frac{\int_{0}^{c} \mathrm{a}(\mathrm{c}-\mathrm{a}) \theta^{\mathrm{e}} \mathrm{e}^{-\theta(\mathrm{at+nk})} \mathrm{da}}{\Gamma(\mathrm{w}+1) \int_{0}^{c} \mathrm{a}(\mathrm{c}-\mathrm{a})[\mathrm{a}+\mathrm{nk}]^{-(\mathrm{w}+1)} \mathrm{da}},
\end{aligned}
$$

\subsection{The quasi-hierarchical Bayesian estimation under squared error loss function (SELF)}

The quasi-hierarchical Bayes estimates of $\theta$ based on SELF denoted by $\hat{\theta}_{\text {QнBSi }}(i=1,2,3)$ can be obtained as

$$
\hat{\theta}_{\text {OHBSi }}=\mathrm{E}_{\mathrm{h}_{\mathrm{i}}}(\theta \mid \underline{\mathrm{x}}), \quad \mathrm{i}=1,2,3
$$

Where $E_{h_{i}}$ referred to the expectation of the quasi hierarchical posterior distribution. We can derived $\hat{\theta}_{\text {Онві }}(\mathrm{i}=1,2,3)$ by using (44), (4-5) and (4-6) in (4-7) to be

$$
\begin{aligned}
& \hat{\theta}_{\text {QHвS1 }}=\frac{(\mathrm{w}+1) \int_{0}^{c} \mathrm{a}[\mathrm{a}+\mathrm{nk}]^{-(\mathrm{w}+2)} \mathrm{da}}{\int_{0}^{c} \mathrm{a}[\mathrm{a}+\mathrm{nk}]^{-(\mathrm{w}+1)} \mathrm{da}}, \\
& \hat{\theta}_{\text {QнBS } 2}=\frac{(\mathrm{w}+1) \int_{0}^{c} \mathrm{a}^{2}[\mathrm{a}+\mathrm{nk}]^{-(\mathrm{w}+2)} \mathrm{da}}{\int_{0}^{c} \mathrm{a}^{2}[\mathrm{a}+\mathrm{nk}]^{-(\mathrm{w}+1)} \mathrm{da}},
\end{aligned}
$$

And

$$
\hat{\theta}_{\text {OнBз }}=\frac{(\mathrm{w}+1) \int_{0}^{c} \mathrm{a}(\mathrm{c}-\mathrm{a})[\mathrm{a}+\mathrm{nk}]^{-(\mathrm{w}+2)} \mathrm{da}}{\int_{0}^{c} \mathrm{a}(\mathrm{c}-\mathrm{a})[\mathrm{a}+\mathrm{nk}]^{-(\mathrm{w}+1)} \mathrm{da}},
$$

Unfortunately, there is no closed form for $\hat{\theta}_{\text {Рнві }}(i=1,2,3)$ given in (4-8), (4-9) and (4-10). So, numerical computations and computer facilities are needed for calculating $\hat{\theta}_{\text {онвs }}(i=1,2,3)$.

\subsection{The quasi-hierarchical Bayesian estimation under precautionary loss function (PLF)}

The quasi-hierarchical Bayes estimates of $\theta$ based on QLF denoted by $\hat{\theta}_{\text {Рнві }}(i=1,2,3)$ can be obtained as

$$
\hat{\theta}_{\text {онвві }}=\left[\mathrm{E}_{\mathrm{h}_{\mathrm{i}}}\left(\theta^{2} \mid \underline{\mathrm{x}}\right)\right]^{\frac{1}{2}}, \quad \mathrm{i}=(1,2,3)
$$

We can derived $\hat{\theta}_{\text {онве }}(\mathrm{i}=1,2,3)$ by using (4-4), (4-5) and (4-6) in (411) to be

$$
\hat{\theta}_{\text {онРP1 }}=\sqrt{\frac{(w+1)(w+2) \int_{0}^{c} a[a+n k]^{-(w+3)}}{\int_{0}^{c} a[a+n k]^{-(w+1)}}},
$$




$$
\hat{\theta}_{\mathrm{QHBP} 2}=\sqrt{\frac{(\mathrm{w}+1)(\mathrm{w}+2) \int_{0}^{\mathrm{c}} \mathrm{a}^{2}[\mathrm{a}+\mathrm{nk}]^{-(\mathrm{w}+3)}}{\int_{0}^{\mathrm{c}} \mathrm{a}^{2}[\mathrm{a}+\mathrm{nk}]^{-(\mathrm{w}+1)}}},
$$

And

$$
\hat{\theta}_{\text {ОНвР3 }}=\sqrt{\frac{(\mathrm{w}+1)(\mathrm{w}+2) \int_{0}^{\mathrm{c}} \mathrm{a}(\mathrm{c}-\mathrm{a})[\mathrm{a}+\mathrm{nk}]^{-(\mathrm{w}+3)}}{\int_{0}^{\mathrm{c}} \mathrm{a}(\mathrm{c}-\mathrm{a})[\mathrm{a}+\mathrm{nk}]^{-(\mathrm{w}+1)}}},
$$

The integrals in (4-12), (4-13) and (4-14) cannot be computed analytically in simple closed form, it calculating numerically by using computer facilities.

\subsection{The quasi-hierarchical Bayesian estimation under entropy loss Function (ELF)}

The quasi-hierarchical Bayes estimates of $\theta$ based on ELF denoted by $\hat{\theta}_{\text {онві }}(i=1,2,3)$ can be obtained as

$$
\hat{\theta}_{\text {QнBË }}=\left[\mathrm{E}_{\mathrm{h}_{\mathrm{i}}}\left(\theta^{-1} \mid \underline{\mathbf{x}}\right)\right]^{-1} \quad \mathrm{i}=1,2,3
$$

We can derived $\hat{\theta}_{\text {Qнві }}(i=1,2,3)$ by using (4-4), (4-5) and (4-6) in (4-15) to be

$$
\begin{aligned}
& \hat{\theta}_{\text {ОНвЕ1 }}=\frac{w \int_{0}^{c} a[a+n k]^{-(w+1)} d a}{\int_{0}^{c} a[a+n k]^{-w} d a}, \\
& \hat{\theta}_{\text {ОНBE } 2}=\frac{w \int_{0}^{c} a^{2}[a+n k]^{-(w+1)} d a}{\int_{0}^{c} a^{2}[a+n k]^{-w} d a},
\end{aligned}
$$

And

$$
\hat{\theta}_{\text {Qнве } 3}=\frac{\mathrm{w} \int_{0}^{c} \mathrm{a}(\mathrm{c}-\mathrm{a})[\mathrm{a}+\mathrm{nk}]^{-(\mathrm{w}+1)} \mathrm{da}}{\int_{0}^{c} \mathrm{a}(\mathrm{c}-\mathrm{a})[\mathrm{a}+\mathrm{nk}]^{-\mathrm{w}} \mathrm{da}},
$$

Also, there is no closed form for $\hat{\theta}_{\text {Qнві }}(i=1,2,3)$ given in (4-16), (417) and (4-18). So, numerical computations and computer facilities are needed for calculating $\hat{\theta}_{\text {онві }}(i=1,2,3)$.

\subsection{The quasi-hierarchical Bayesian estimation under Degroot loss function (DLF)}

The quasi-hierarchical Bayes estimates of $\theta$ based on DLF denoted by $\hat{\theta}_{\text {онврі }}(i=1,2,3)$ can be obtained as

$$
\hat{\theta}_{\text {OHBDi }}=\frac{\mathrm{E}_{\mathrm{h}_{\mathrm{i}}}\left(\theta^{2} \mid \underline{\mathrm{x}}\right)}{\mathrm{E}_{\mathrm{h}_{\mathrm{i}}}(\theta \mid \underline{\mathrm{x}})} \quad \mathrm{i}=1,2,3
$$

We can derived $\hat{\theta}_{\text {QHВі }}(i=1,2,3)$ by using (4-4), (4-5) and (4-6) in (4-19) to be

$$
\begin{aligned}
& \hat{\theta}_{\text {ОНВD1 }}=\frac{(\mathrm{w}+2) \int_{0}^{\mathrm{c}} \mathrm{a}[\mathrm{a}+\mathrm{nk}]^{-(\mathrm{w}+3)} \mathrm{da}}{\int_{0}^{\mathrm{c}} \mathrm{a}[\mathrm{a}+\mathrm{nk}]^{-(\mathrm{w}+2)} \mathrm{da}}, \\
& \hat{\theta}_{\text {QнВD2}}=\frac{(\mathrm{w}+2) \int_{0}^{c} \mathrm{a}^{2}[\mathrm{a}+\mathrm{nk}]^{-(\mathrm{w}+3)} \mathrm{da}}{\int_{0}^{\mathrm{c}} \mathrm{a}^{2}[\mathrm{a}+\mathrm{nk}]^{-(\mathrm{w}+2)} \mathrm{da}},
\end{aligned}
$$

And

$$
\hat{\theta}_{\text {онвВ3 }}=\frac{(\mathrm{w}+2) \int_{0}^{\mathrm{c}} \mathrm{a}(\mathrm{c}-\mathrm{a})[\mathrm{a}+\mathrm{nk}]^{-(\mathrm{w}+3)} \mathrm{da}}{\int_{0}^{c} \mathrm{a}(\mathrm{c}-\mathrm{a})[\mathrm{a}+\mathrm{nk}]^{-(\mathrm{w}+2)} \mathrm{da}},
$$

The integrals in (4-20), (4-21) and (4-22) are very complicated and cannot be solved analytically in simple closed form, it calculating numerically by using computer facilities.

\subsection{The quasi-hierarchical Bayesian estimation under quadratic loss function (QLF)}

The quasi-hierarchical Bayes estimates of $\theta$ based on QLF denoted by $\hat{\theta}_{\text {онвоі }}(i=1,2,3)$ can be obtained as

$$
\hat{\theta}_{\text {онВеi }}=\frac{\mathrm{E}_{\mathrm{hi}_{\mathrm{i}}}\left(\theta^{-1} \mid \underline{\mathrm{x}}\right)}{\mathrm{E}_{\mathrm{h}_{\mathrm{i}}}\left(\theta^{-2} \mid \underline{\mathrm{x}}\right)} \quad \mathrm{i}=1,2,3
$$

We can derived $\hat{\theta}_{\text {Рнві }}(\mathrm{i}=1,2,3)$ by using (4-4), (4-5) and (4-6) in (4-23) to be

$$
\begin{aligned}
& \hat{\theta}_{\text {Онве1 }}=\frac{(\mathrm{w}-1) \int_{0}^{c} \mathrm{a}[\mathrm{a}+\mathrm{nk}]^{-\mathrm{w}} \mathrm{da}}{\int_{0}^{\mathrm{c}} \mathrm{a}[\mathrm{a}+\mathrm{nk}]^{-(\mathrm{w}-1)} \mathrm{da}}, \\
& \hat{\theta}_{\text {енвQ2 }}=\frac{(\mathrm{w}-1) \int_{0}^{c} \mathrm{a}^{2}[\mathrm{a}+\mathrm{nk}]^{-\mathrm{w}} \mathrm{da}}{\int_{0}^{c} \mathrm{a}^{2}[\mathrm{a}+\mathrm{nk}]^{(\mathrm{w}-1)} \mathrm{da}},
\end{aligned}
$$

And

$$
\hat{\theta}_{\text {онВе3 }}=\frac{(\mathrm{w}-1) \int_{0}^{\mathrm{c}} \mathrm{a}(\mathrm{c}-\mathrm{a})[\mathrm{a}+\mathrm{nk}]^{-\mathrm{w}} \mathrm{da}}{\int_{0}^{\mathrm{c}} \mathrm{a}(\mathrm{c}-\mathrm{a})[\mathrm{a}+\mathrm{nk}]^{(\mathrm{w}-1)} \mathrm{da}},
$$

The integrals in (4-24), (4-25) and (4-26) are very complicated and cannot be solved analytically in simple closed form, it calculating numerically by using computer facilities.

\section{The quasi-empirical Bayesian estimation}

In this section, we have concerned to obtain the quasi-empirical Bayes estimates for the scale parameter of the Erlang distribution by considering symmetric loss function [squared error loss (SELF))] and four different asymmetric loss functions [Precautionary loss function (PLF), entropy loss function (ELF), Degroot loss function (DLF) and quadratic loss function (QLF)]. The Bayes approach assumed that the hyper parameter a is known. When a is unknown, we may use the empirical Bayes criteria to get its estimates from the likelihood function and probability density function of the prior distribution [33].Now, from (2-7) and (29 ), the marginal distribution of $\mathrm{x}$ given a is obtained as:

$$
\mathrm{f}(\mathrm{x} \mid \mathrm{a}) \propto \int_{0}^{\infty} \exp [\mathrm{Q}(\mathrm{x} ; \theta)] \mathrm{g}(\theta \mid \mathrm{a}) \mathrm{d} \theta \propto \mathrm{a}(\mathrm{a}+\mathrm{nk})^{-(\mathrm{w}+1)}
$$

By taking the natural log for (5-1), we get

$$
\log f(x \mid a) \propto \log a-(w+1) \log \Gamma(a+n k)
$$

By taking the derivative for (5-2) and setting it equal to zero, we obtain

$$
\left.\frac{\partial \log f(x \mid a)}{\partial a}\right|_{a=\bar{a}}=\frac{1}{\tilde{a}}-\frac{(w+1)}{\tilde{a}+n k}=0
$$

By solving (5-3) for ã which is the quasi-maximum likelihood estimator of a to be

$$
\tilde{\mathrm{a}}=\frac{\mathrm{nk}}{\mathrm{w}}
$$


5.1. The quasi-empirical Bayesian estimation under squared error loss function (SELF)

The quasi-empirical Bayes estimate of $\theta$ based on SELF denoted as $\hat{\theta}_{\text {o:Bs }}$ can be obtained by replacing a in (5-4) instead of a in (213) to be

$$
\hat{\theta}_{\text {QeBs }}=\frac{\mathrm{w}}{\mathrm{nk}}
$$

5.2. The quasi-empirical estimation under precautionary loss function (PLF)

The quasi-empirical Bayes estimate of $\theta$ based on PLF denoted as $\hat{\theta}_{\text {QRBP }}$ can be obtained by replacing ã in (5-4) instead of a in (216) to be

$$
\hat{\theta}_{\text {eEBP }}=\left(\frac{\mathrm{w}}{\mathrm{nk}}\right) \sqrt{\frac{\mathrm{w}+2}{\mathrm{w}+1}}
$$

\subsection{The quasi-empirical estimation under entropy loss} function (ELF)

The quasi-empirical Bayes estimate of $\theta$ based on ELF denoted as $\hat{\theta}_{\text {Q } \mathrm{CBE}}$ can be obtained by replacing a in (5-4) instead of a in (219) to be

$$
\hat{\theta}_{\text {QeBE }}=\frac{\mathrm{w}^{2}}{\mathrm{nk}(\mathrm{w}+1)}
$$

5.4. The quasi-empirical Bayesian estimation under degroot loss function (DLF)

The quasi-empirical Bayes estimate of $\theta$ based on DLF denoted as $\hat{\theta}_{\text {o } \mathrm{BD}}$ can be obtained by replacing a in (5-4) instead of a in (2-22) to be

$$
\hat{\theta}_{\text {QeBD }}=\frac{\mathrm{w}(\mathrm{w}+2)}{\mathrm{nk}(\mathrm{w}+1)}
$$

5.5. The quasi-empirical Bayesian estimation under quadratic loss function (QLF)

The quasi-empirical Bayes estimate of $\theta$ based on DLF denoted as $\hat{\theta}_{\text {овв }}$ can be obtained by replacing a in (5-4) instead of a in (2-25) to be

$$
\hat{\theta}_{\text {QевQ }}=\frac{\mathrm{w}(\mathrm{w}-1)}{\mathrm{nk}(\mathrm{w}+1)}
$$

\section{Properties of quasi-E-Bayesian estimation}

In this section, we discuss the relations between the QE-Bayesian estimators and the relation between the QE-Bayesian estimators and the quasi-hierarchical Bayesian estimators.

\subsection{The relations between the QE-Bayesian estimates}

In this subsection, we shall derive the relation the QE-Bayesian estimates.

6.1.1. Relations among $\hat{\theta}_{\text {QEBSi }}(i=1,2,3)$ i) $\hat{\theta}_{\text {QEBS2 }}<\hat{\theta}_{\text {QEBS1 }}<\hat{\theta}_{\text {QEBS3 }}$

ii) $\lim _{\mathrm{n} k \rightarrow \infty} \hat{\theta}_{\text {QEBS1 }}=\lim _{\mathrm{n} \rightarrow \rightarrow \infty} \hat{\theta}_{\text {QEBS2 }}=\lim _{\mathrm{n} k \rightarrow \infty} \hat{\theta}_{\text {QEBS3 }}$

Proof. See Appendix (1).

6.1.2. Relations among $\hat{\theta}_{\mathrm{PBBP}}(\mathrm{i}=1,2,3)$

Lemma 2: It follows from (3-9), (3-10) and (3-11) that
i) $\quad \hat{\theta}_{\text {QEBP2 }}<\hat{\theta}_{\text {QEBP1 }}<\hat{\theta}_{\text {QEBP3 }}$
ii) $\lim _{n k \rightarrow \infty} \hat{\theta}_{\text {QEBP1 }}=\lim _{\mathrm{nk} \rightarrow \infty} \hat{\theta}_{\text {QEBP2 }}=\lim _{\mathrm{n} k \rightarrow \infty} \hat{\theta}_{\text {QEBP3 }}$

Proof. See Appendix (1).

6.1.3. Relations among $\hat{\theta}_{\mathrm{OEBE}}(i=1,2,3)$

Lemma 3: It follows from (3-12), (3-13) and (3-14) that

i) $\hat{\theta}_{\text {QЕBE2 }}<\hat{\theta}_{\text {QевE1 }}<\hat{\theta}_{\text {QевE3 }}$

ii) $\lim _{n k \rightarrow \infty} \hat{\theta}_{\text {QEBE1 }}=\lim _{n k \rightarrow \infty} \hat{\theta}_{\text {QEBE2 } 2}=\lim _{n k \rightarrow \infty} \hat{\theta}_{\text {QEBE3 }}$

Proof. See Appendix (1).

6.1.4. Relations among $\hat{\theta}_{\text {оввD }}(i=1,2,3)$

Lemma 4: It follows from (3-15), (3-16) and (3-17) that

i) $\quad \hat{\theta}_{\text {OЕBD2 }}<\hat{\theta}_{\mathrm{OEBD} 1}<\hat{\theta}_{\mathrm{OEBD} 3}$

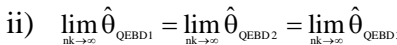

Proof. See Appendix (1).

6.1.5. Relations among $\hat{\theta}_{\text {оввоi }}(i=1,2,3)$

Lemma 5: It follows from (3-18), (3-19) and (3-20) that
i) $\quad \hat{\theta}_{\text {QЕBQ2 }}<\hat{\theta}_{\text {QEBQ1 }}<\hat{\theta}_{\text {QEBQ3 }}$
ii) $\lim _{\mathrm{nk} \rightarrow \infty} \hat{\theta}_{\mathrm{QEBQ1}}=\lim _{\mathrm{n} k \rightarrow \infty} \hat{\theta}_{\mathrm{QEBQ2}}=\lim _{\mathrm{n} k \rightarrow \infty} \hat{\theta}_{\mathrm{QEBQ} 3}$

Proof. See Appendix (1).

6.2. The relations between the QE-Bayesian and quasihierarchical Bayesian estimates

In this subsection, we shall construct the relations between the QE-Bayesian and the quasi-hierarchical Bayesian estimates.

6.2.1. Relations among $\hat{\theta}_{\text {QЕBSi }}, \hat{\theta}_{\text {OнBSi }}(i=1,2,3)$

Lemma 6: It follows from (3-6), (3-7), (3-8), (4-8). (4-9) and (410) that

$\lim _{n \in \rightarrow \infty} \hat{\theta}_{\text {QEBSi }}=\lim _{\text {nik } \rightarrow \infty} \hat{\theta}_{\text {OHBS }}(\mathrm{i}=1,2,3)$ 
Proof. See Appendix (2).

6.2.2. Relations among $\hat{\theta}_{\text {огеві }}, \hat{\theta}_{\text {онве }}(i=1,2,3)$

Lemma 7: It follows from (3-9), (3-10), (3-11), (4-12). (4-13) and (4-14) that

$\lim _{n k \rightarrow \infty} \hat{\theta}_{\text {QЕBP }}=\lim _{n \in \rightarrow \infty} \hat{\theta}_{\text {OHBP }}(\mathrm{i}=1,2,3)$

Proof. See Appendix (2).

6.2.3. Relations among $\hat{\theta}_{\mathrm{QЕBE}}, \hat{\theta}_{\text {РнЁ }}(i=1,2,3)$

Lemma 8: It follows from (3-12), (3-13), (3-14), (4-16). (4-17) and (4-18) that

$\lim _{n k \rightarrow \infty} \hat{\theta}_{\text {QвBEi }}=\lim _{n k \rightarrow \infty} \hat{\theta}_{\text {Qнвві }}(\mathrm{i}=1,2,3)$

Proof. See Appendix (2)

6.2.4. Relations among $\hat{\theta}_{\text {РввDi }}, \hat{\theta}_{\text {онві }}(i=1,2,3)$

Lemma 9: It follows from (3-15), (3-16), (3-17), (4-20). (4-21) and (4-22) that

$\lim _{\mathrm{nk} \rightarrow \infty} \hat{\theta}_{\text {QEBDi }}=\lim _{\mathrm{nk} \rightarrow \infty} \hat{\theta}_{\text {OHBDi }}(\mathrm{i}=1,2,3)$

Proof. See Appendix (2)

6.2.5. Relations among $\hat{\theta}_{\text {Рвві, }}, \hat{\theta}_{\text {онвеі }}(\mathrm{i}=1,2,3)$

Lemma 10: It follows from (3-18), (3-19), (3-20), (4-24). (4-25) and (4-26) that

$\lim _{\mathrm{n} k \rightarrow \infty} \hat{\theta}_{\text {QвBQi }}=\lim _{\text {nk } \rightarrow \infty} \hat{\theta}_{\text {Qнвеi }}(\mathrm{i}=1,2,3)$

Proof. See Appendix (2).

\section{Monte Carlo simulation}

This section investigated a Monte Carlo simulation study to evaluate the performance of different estimators for the scale parameter corresponding to the Erlang distribution discussed in the preceding sections. The simulation structure consists of five basic steps which are:

Step (1): Set the default values (true values) of $\mathrm{k}$ and $\mathrm{c}$ which are 3 and 5 respectively. We considered different sample sizes to observe their effect on the estimates in small, moderate and large dataset which are

\begin{tabular}{clll}
\hline & small samples & moderate samples & large samples \\
\hline $\mathrm{n}$ & 5,10 & $15,20,25$ & $40,50,60,70$ \\
\hline
\end{tabular}

Step (2): For these cases, we generate a from the uniform prior distributions $(0, \mathrm{c})$ given in (3-3), (3-4) and (3-5). For given values of a, we generate $\theta$ from the exponential prior distribution given in (2-9).

Step (3): For known values of k, samples are generated from the Erlang distribution given in (1-1) through the adoption of inverse transformation method, by solving the following equation numerically

$\mathrm{U}_{\mathrm{i}}=1-\sum_{\mathrm{i}=1}^{k-1} \frac{\mathrm{e}^{\frac{-x_{i}}{\theta}} \mathrm{x}^{\mathrm{i}}}{\theta^{i} \mathrm{i} !}$

Where $\mathrm{U}$ is a random variable distributed according to uniform distribution on the period $(0,1)$.
Step (4): Calculate the quasi-Bayes, QE-Bayes, quasi-hierarchical Bayes and quasi-empirical Bayes estimates of the unknown scale parameter associated to the Erlang distribution according to the formulas that have been obtained.

Step (5): We repeated this process 1000 times and compute the mean square error (MSE) for the estimates for different sample sizes and given values of $\mathrm{k}, \mathrm{c}$ where

$\operatorname{MSE}(\hat{\theta})=\frac{1}{1000} \sum(\hat{\theta}-\theta)^{2}$

And $\hat{\theta}$ stands for an estimator of $\theta$. The simulation results are displayed in Tables (1-5).

Table 1: Averaged Values of MSES for Estimates of the Parameter $\theta$ Based On SELF

\begin{tabular}{|c|c|c|c|c|}
\hline $\mathrm{n}$ & $\hat{\theta}_{\mathrm{QBS}}$ & $\hat{\theta}_{\text {QEBS }}$ & $\hat{\theta}_{\text {онBS }}$ & $\hat{\theta}_{\text {QeBS }}$ \\
\hline \multirow{4}{*}{5} & \multirow{3}{*}{0.0072705} & 0.0073777 & 0.0077262 & \multirow{3}{*}{0.0098880} \\
\hline & & 0.0069077 & 0.0072920 & \\
\hline & & 0.0085891 & 0.0083999 & \\
\hline & \multirow{4}{*}{0.0045925} & 0.0046096 & 0.0047305 & \multirow{3}{*}{0.0053885} \\
\hline \multirow[t]{3}{*}{10} & & 0.0044600 & 0.0045935 & \\
\hline & & 0.0049660 & 0.0049238 & \\
\hline & & 0.0028348 & 0.0087886 & \multirow{3}{*}{0.0031496} \\
\hline \multirow[t]{2}{*}{15} & 0.0028292 & 0.0075598 & 0.0028121 & \\
\hline & & 0.0030098 & 0.0029786 & \\
\hline \multirow{4}{*}{20} & 0.0022433 & 0.0022458 & 0.0022718 & \multirow{3}{*}{0.0024322} \\
\hline & 0.0022433 & 0.0021943 & 0.0022284 & \\
\hline & & 0.0023526 & 0.0023334 & \\
\hline & & 0.0020058 & 0.0020234 & \multirow{4}{*}{0.0021385} \\
\hline \multirow[t]{3}{*}{25} & 0.0020043 & 0.0019642 & 0.0019890 & \\
\hline & & 0.0020832 & 0.0020695 & \\
\hline & & 0.0011308 & 0.0011384 & \\
\hline \multirow[t]{3}{*}{40} & 0.0011306 & 0.0011219 & 0.0011306 & \multirow[t]{3}{*}{0.0011781} \\
\hline & & 0.0011538 & 0.0011505 & \\
\hline & & 0.0009948 & 0.0010002 & \\
\hline \multirow[t]{3}{*}{50} & 0.0009947 & 0.0009882 & 0.0009944 & \multirow[t]{3}{*}{0.0010281} \\
\hline & & 0.0010105 & 0.0010086 & \\
\hline & & 0.0008254 & 0.0008291 & \\
\hline \multirow[t]{3}{*}{60} & 0.0008254 & 0.0008205 & 0.0008248 & \multirow[t]{3}{*}{0.0008484} \\
\hline & & 0.0008367 & 0.0008352 & \\
\hline & & 0.0007447 & 0.0007474 & \\
\hline \multirow[t]{2}{*}{70} & 0.0007448 & 0.0007374 & 0.0007411 & \multirow[t]{2}{*}{0.0007628} \\
\hline & & 0.0007573 & 0.0007549 & \\
\hline
\end{tabular}

Table 2: Averaged Values of MSES for Estimates of the Parameter $\theta$ Based On PLF

\begin{tabular}{|c|c|c|c|c|}
\hline $\mathrm{n}$ & $\hat{\theta}_{\mathrm{QBS}}$ & $\hat{\theta}_{\text {QEBS }}$ & $\hat{\theta}_{\text {онвS }}$ & $\hat{\theta}_{\text {QeBs }}$ \\
\hline \multirow{4}{*}{5} & \multirow{3}{*}{0.0081230} & 0.0083826 & 0.0085543 & \multirow{3}{*}{0.0108437} \\
\hline & & 0.0068340 & 0.0073084 & \\
\hline & & 0.0107762 & 0.0101781 & \\
\hline & & 0.0048693 & 0.0049241 & \multirow{4}{*}{0.0056291} \\
\hline \multirow[t]{3}{*}{10} & \multirow[t]{3}{*}{0.0048303} & 0.0044121 & 0.0045627 & \\
\hline & & 0.0055492 & 0.0053834 & \\
\hline & & 0.0029865 & 0.0029962 & \\
\hline \multirow[t]{3}{*}{15} & \multirow[t]{3}{*}{0.0029742} & 0.0027628 & 0.0028248 & \multirow[t]{3}{*}{0.0032918} \\
\hline & & 0.0033115 & 0.0032207 & \\
\hline & & 0.0023389 & 0.0023439 & \\
\hline \multirow[t]{3}{*}{20} & \multirow[t]{3}{*}{0.0023336} & 0.0022037 & 0.0022408 & \multirow[t]{3}{*}{0.0025197} \\
\hline & & 0.0025316 & 0.0024777 & \\
\hline & & 0.0020722 & 0.0020763 & \\
\hline \multirow[t]{3}{*}{25} & \multirow[t]{3}{*}{0.002069} & 0.0019763 & 0.0020029 & \multirow[t]{2}{*}{0.0022016} \\
\hline & & 0.0022053 & 0.0021691 & \\
\hline & & 0.0011483 & 0.0011501 & \\
\hline \multirow[t]{3}{*}{40} & \multirow[t]{3}{*}{0.0011478} & 0.0011178 & 0.0011269 & \multirow[t]{2}{*}{0.0011938} \\
\hline & & 0.0011932 & 0.0011807 & \\
\hline & & 0.0010060 & 0.0010076 & \multirow{4}{*}{0.0010381} \\
\hline \multirow[t]{3}{*}{50} & \multirow[t]{3}{*}{0.0010058} & 0.0009854 & 0.0009919 & \\
\hline & & 0.0010358 & 0.0010279 & \\
\hline & & 0.0008338 & 0.0008348 & \\
\hline \multirow[t]{3}{*}{60} & 0.0008337 & 0.0008191 & 0.0008236 & \multirow[t]{3}{*}{0.0008560} \\
\hline & & 0.0008549 & 0.0008493 & \\
\hline & & 0.0007562 & 0.0007568 & \\
\hline \multirow[t]{2}{*}{70} & 0.0007563 & 0.0007412 & 0.0007454 & \multirow[t]{2}{*}{0.0007750} \\
\hline & & 0.0007765 & 0.0007711 & \\
\hline
\end{tabular}


Table 3: Averaged Values of MSES for Estimates of the Parameter $\theta$ Based On ELF

\begin{tabular}{|c|c|c|c|c|}
\hline $\mathrm{n}$ & $\hat{\theta}_{\mathrm{QBS}}$ & $\hat{\theta}_{\mathrm{QEBS}}$ & $\hat{\theta}_{\text {РнвS }}$ & $\hat{\theta}_{\text {QeBS }}$ \\
\hline \multirow{4}{*}{5} & \multirow{4}{*}{0.104182} & 0.1027392 & 0.0111718 & \multirow{3}{*}{0.012716} \\
\hline & & 0.0115754 & 0.0119868 & \\
\hline & & 0.0095218 & 0.0102227 & \\
\hline & & 0.0055100 & 0.0057961 & \multirow{3}{*}{0.0063097} \\
\hline \multirow[t]{3}{*}{10} & 0.0055325 & 0.0059153 & 0.0060511 & \\
\hline & & 0.0052810 & 0.0054976 & \\
\hline & & 0.0031945 & 0.0033184 & \multirow{3}{*}{0.003524} \\
\hline \multirow[t]{3}{*}{15} & 0.0032013 & 0.0033861 & 0.0034427 & \\
\hline & & 0.0030891 & 0.0031809 & \\
\hline & & 0.0024427 & 0.0025146 & \multirow{3}{*}{0.002638} \\
\hline \multirow[t]{3}{*}{20} & 0.0024455 & 0.0025500 & 0.0025839 & \\
\hline & & 0.0023864 & 0.0024382 & \\
\hline & & 0.0021221 & 0.0021695 & \multirow{3}{*}{$0.002260^{-}$} \\
\hline \multirow[t]{3}{*}{25} & 0.0021319 & 0.0021849 & 0.0022091 & \\
\hline & & 0.0020927 & 0.0021251 & \\
\hline & & 0.0011957 & 0.0012156 & \multirow{4}{*}{0.0012463} \\
\hline \multirow[t]{3}{*}{40} & 0.0011960 & 0.0012289 & 0.0012375 & \\
\hline & & 0.0011761 & 0.0011914 & \\
\hline & & 0.0010369 & 0.0010503 & \\
\hline \multirow[t]{3}{*}{50} & 0.0010371 & 0.0010576 & 0.0010637 & \multirow[t]{3}{*}{0.0010723} \\
\hline & & 0.0010250 & 0.0010351 & \\
\hline & & 0.0008536 & 0.0149875 & \\
\hline \multirow[t]{3}{*}{60} & 0.0008537 & 0.0008678 & 0.0008721 & \multirow[t]{3}{*}{0.0008781} \\
\hline & & 0.0008456 & 0.0008525 & \\
\hline & & 0.0007548 & 0.0007609 & \\
\hline \multirow[t]{2}{*}{70} & 0.0007548 & 0.0007626 & 0.0007657 & \multirow[t]{2}{*}{0.000771} \\
\hline & & 0.0007523 & 0.0007560 & \\
\hline
\end{tabular}

Table 4: Averaged Values of MSES for Estimates of the Parameter $\theta$ Based On DLF

\begin{tabular}{|c|c|c|c|c|}
\hline $\mathrm{n}$ & $\hat{\theta}_{\mathrm{QBS}}$ & $\hat{\theta}_{\text {QEBS }}$ & $\hat{\theta}_{\text {онвS }}$ & $\hat{\theta}_{\text {QRBS }}$ \\
\hline \multirow{4}{*}{5} & \multirow{3}{*}{$0.0106578)$} & 0.0111023 & 0.0111747 & \multirow{3}{*}{0.0134368} \\
\hline & & 0.0082421 & 0.0089068 & \\
\hline & & 0.0149265 & 0.0139237 & \\
\hline & & 0.0056102 & 0.0056088 & \multirow{4}{*}{0.0063425} \\
\hline \multirow[t]{3}{*}{10} & 0.0055466 & 0.0048092 & 0.0049916 & \\
\hline & & 0.0066509 & 0.0063605 & \\
\hline & & 0.0033633 & 0.0033416 & \\
\hline \multirow[t]{3}{*}{15} & 0.0033437 & 0.0029831 & 0.0030557 & \multirow[t]{3}{*}{0.0036571} \\
\hline & & 0.0038501 & 0.0036993 & \\
\hline & & 0.0025615 & 0.0025472 & \\
\hline \multirow[t]{3}{*}{20} & 0.0025532 & 0.0023375 & 0.0023796 & \multirow[t]{3}{*}{0.0027361} \\
\hline & & 0.0028452 & 0.0027564 & \\
\hline & & 0.0022227 & 0.0022139 & \\
\hline \multirow[t]{3}{*}{25} & 0.0022184 & 0.0020696 & 0.0020991 & \multirow[t]{3}{*}{0.0023484} \\
\hline & & 0.0024141 & 0.0023552 & \\
\hline & & 0.0011992 & 0.0011953 & \\
\hline \multirow[t]{3}{*}{40} & 0.0011984 & 0.0011464 & 0.0015622 & \multirow[t]{3}{*}{0.0012429} \\
\hline & & 0.0012667 & 0.0012450 & \\
\hline & & 0.0010387 & 0.0010367 & \\
\hline \multirow[t]{3}{*}{50} & 0.0010384 & 0.0010039 & 0.0010107 & \multirow[t]{2}{*}{0.0010697} \\
\hline & & 0.0010830 & 0.0010691 & \\
\hline & & 0.0008572 & 0.0008556 & \\
\hline \multirow[t]{3}{*}{60} & 0.0008571 & 0.0008326 & 0.0008374 & \multirow[t]{2}{*}{0.0008786} \\
\hline & & 0.0008884 & 0.0008786 & \\
\hline & & 0.0007788 & 0.0007778 & \\
\hline \multirow[t]{2}{*}{70} & 0.0007790 & 0.0007561 & 0.0007607 & \multirow[t]{2}{*}{0.0007984} \\
\hline & & 0.0008070 & 0.0007986 & \\
\hline
\end{tabular}

Table 5: Averaged Values of MSES for Estimates of the Parameter $\theta$ Based On QLF

\begin{tabular}{|c|c|c|c|c|}
\hline $\mathrm{n}$ & $\hat{\theta}_{\mathrm{QBS}}$ & $\hat{\theta}_{\text {QEBS }}$ & $\hat{\theta}_{\text {онвS }}$ & $\hat{\theta}_{\text {QeBS }}$ \\
\hline \multirow{4}{*}{5} & \multirow{4}{*}{0.0201012} & 0.0197914 & 0.0212963 & \multirow{4}{*}{0.0219209} \\
\hline & & 0.0222451 & 0.0228377 & \\
\hline & & 0.0177246 & 0.0192307 & \\
\hline & & 0.0083114 & 0.0087877 & \\
\hline \multirow{3}{*}{10} & \multirow[t]{3}{*}{0.0083667} & 0.0091753 & 0.0093507 & \multirow[t]{2}{*}{0.0091064} \\
\hline & & 0.0075586 & 0.0080694 & \\
\hline & & 0.0044421 & 0.0046563 & \multirow{3}{*}{0.0047814} \\
\hline \multirow[t]{3}{*}{15} & \multirow[t]{2}{*}{0.0044600} & 0.0048733 & 0.0049444 & \\
\hline & & 0.0040879 & 0.0043037 & \\
\hline & & 0.0031522 & 0.0032753 & \multirow{3}{*}{0.0033555} \\
\hline \multirow[t]{2}{*}{20} & 0.0031597 & 0.0034047 & 0.0034448 & \\
\hline & & 0.0029464 & 0.0030700 & \\
\hline
\end{tabular}

\begin{tabular}{|c|c|c|c|c|}
\hline \multirow{3}{*}{25} & & 0.0025715 & 0.0026516 & \multirow{3}{*}{0.0027152} \\
\hline & 0.0025751 & 0.0027317 & 0.0027588 & \\
\hline & & 0.0024427 & 0.0025216 & \\
\hline \multirow{4}{*}{40} & & 0.0013939 & 0.0014269 & \multirow{4}{*}{0.0014477} \\
\hline & 0.0013978 & 0.0014673 & 0.0014768 & \\
\hline & & 0.0013334 & 0.0013675 & \\
\hline & & 0.0011650 & 0.0011867 & \\
\hline \multirow[t]{3}{*}{50} & 0.0011654 & 0.0012121 & 0.0012186 & \multirow[t]{3}{*}{0.0012025} \\
\hline & & 0.0011265 & 0.0011486 & \\
\hline & & 0.0009419 & 0.0009569 & \\
\hline \multirow[t]{3}{*}{60} & 0.0009421 & 0.0009747 & 0.0009791 & \multirow[t]{3}{*}{0.0009678} \\
\hline & & 0.0009151 & 0.0009304 & \\
\hline & & 0.0008093 & 0.0008191 & \\
\hline \multirow[t]{2}{*}{70} & 0.0008091 & 0.0008317 & 0.0008345 & \multirow[t]{2}{*}{0.0008245} \\
\hline & & 0.0007919 & 0.0008017 & \\
\hline
\end{tabular}

8. Conclusion remarks

- Among four estimates of $\theta$ based on different loss functions shown in Tables (1-5), we can deducted that the QEBayes estimates are the best whereas the quasi-empirical estimators are the worst. Generally, the overall performance of the four techniques for estimating $\theta$ can be ordered due to number of having smaller MSE as follows:

$$
\hat{\theta}_{\text {QEBS }}>\hat{\theta}_{\text {OHBS }}>\hat{\theta}_{\text {QBS }}>\hat{\theta}_{\text {QеBS }}
$$

- In addition, if we comparing the different QE-Bayes estimates in terms of MSE, we can concluded that the QEBayes estimates based on PLF are the most efficient in small and large sample sizes, the QE-Bayes estimates based on SELF are the most efficient in moderate sample sizes while the QE-Bayes estimates based on QLF least efficient in all sample sizes.

- Finally, the results obtained from the numerical results showed that the proposed criteria have more efficient estimators against the other three methods and it easy to operate. The authors want to point out one restriction in applying the suggested method which it can be used only for distributions have an explicit relationship between their mean and variance due to it depends on the quasi-likelihood function.

\section{Appendix (1)}

\section{Proof of Lemma 1}

i) From (3-6), (3-7) and (3-8), we get

$$
\hat{\theta}_{\text {QEBS1 }}-\hat{\theta}_{\text {QEBS2 }}=\hat{\theta}_{\text {QEBS3 }}-\hat{\theta}_{\text {QEBS1 }}=\left(\frac{\mathrm{w}+1}{\mathrm{c}}\right)\left[\left(1+\frac{2 \mathrm{nk}}{\mathrm{c}}\right) \ln \left(1+\frac{\mathrm{c}}{\mathrm{nk}}\right)-2\right]
$$

For $-1<x<1$, we have: $\ln (1+x)=x-\frac{x^{2}}{2}+\frac{x^{3}}{3}-\frac{x^{4}}{4}+\ldots=\sum_{k=1}^{\infty}(-1)^{k-1} \frac{x^{k}}{k}$. Assuming $\mathrm{x}=\frac{\mathrm{c}}{\mathrm{nk}}$ when $0<\mathrm{c}<\mathrm{nk}, 0<\frac{\mathrm{c}}{\mathrm{nk}}<1$, we get

$\left(1+\frac{2 \mathrm{nk}}{\mathrm{c}}\right) \ln \left(1+\frac{\mathrm{c}}{\mathrm{nk}}\right)-2=$

$\left(1+\frac{2 n k}{c}\right)\left[\begin{array}{l}\frac{c}{n k}-\frac{1}{2}\left(\frac{c^{2}}{n^{2} k^{2}}\right)+\frac{1}{3}\left(\frac{c^{3}}{n^{3} k^{3}}\right)- \\ \frac{1}{4}\left(\frac{c^{4}}{n^{4} k^{4}}\right)+\frac{1}{5}\left(\frac{c^{5}}{n^{5} k^{5}}\right)-\frac{1}{6}\left(\frac{c^{6}}{n^{5} k^{5}}\right)+\ldots\end{array}\right]-2$

$=\left[\frac{c}{n k}-\frac{1}{2}\left(\frac{c^{2}}{n^{2} k^{2}}\right)+\frac{1}{3}\left(\frac{c^{3}}{n^{3} k^{3}}\right)-\frac{1}{4}\left(\frac{c^{4}}{n^{4} k^{4}}\right)+\frac{1}{5}\left(\frac{c^{5}}{n^{5} k^{5}}\right)-\ldots\right]-2$ 


$$
\begin{aligned}
& +\left[2-\frac{c}{n k}+\frac{2}{3}\left(\frac{c^{2}}{n^{2} k^{2}}\right)-\frac{2}{4}\left(\frac{c^{3}}{n^{3} k^{3}}\right)+\frac{2}{5}\left(\frac{c^{4}}{n^{4} k^{4}}\right)-\frac{2}{6}\left(\frac{c^{5}}{n^{5} k^{5}}\right)+\ldots\right] \\
& =-\frac{1}{2}\left(\frac{\mathrm{c}^{2}}{\mathrm{n}^{2} \mathrm{k}^{2}}\right)+\frac{1}{3}\left(\frac{\mathrm{c}^{3}}{\mathrm{n}^{3} \mathrm{k}^{3}}\right)-\frac{1}{4}\left(\frac{\mathrm{c}^{4}}{\mathrm{n}^{4} \mathrm{k}^{4}}\right)+\frac{1}{5}\left(\frac{\mathrm{c}^{5}}{\mathrm{n}^{5} \mathrm{k}^{5}}\right)-\ldots \\
& +\frac{2}{3}\left(\frac{c^{2}}{n^{2} k^{2}}\right)-\frac{2}{4}\left(\frac{c^{3}}{n^{3} k^{3}}\right)+\frac{2}{5}\left(\frac{c^{4}}{n^{4} k^{4}}\right)-\frac{2}{6}\left(\frac{c^{5}}{n^{5} k^{5}}\right)+. . \\
& =\left(\frac{2}{3}-\frac{1}{2}\right)\left(\frac{\mathrm{c}^{2}}{\mathrm{n}^{2} \mathrm{k}^{2}}\right)-\left(\frac{2}{4}-\frac{1}{3}\right)\left(\frac{\mathrm{c}^{3}}{\mathrm{n}^{3} \mathrm{k}^{3}}\right)+ \\
& \left(\frac{2}{5}-\frac{1}{4}\right)\left(\frac{\mathrm{c}^{4}}{\mathrm{n}^{4} \mathrm{k}^{4}}\right)-\left(\frac{2}{6}-\frac{1}{5}\right)\left(\frac{\mathrm{c}^{5}}{\mathrm{n}^{5} \mathrm{k}^{5}}\right)+\ldots \\
& =\frac{1}{6}\left(\frac{\mathrm{c}^{2}}{\mathrm{n}^{2} \mathrm{k}^{2}}\right)-\frac{1}{6}\left(\frac{\mathrm{c}^{3}}{\mathrm{n}^{3} \mathrm{k}^{3}}\right)+\frac{3}{20}\left(\frac{\mathrm{c}^{4}}{\mathrm{n}^{4} \mathrm{k}^{4}}\right)-\frac{2}{15}\left(\frac{\mathrm{c}^{5}}{\mathrm{n}^{5} \mathrm{k}^{5}}\right)+\ldots \\
& =\frac{c^{2}}{6 n^{2} k^{2}}\left(1-\frac{c}{n k}\right)-\frac{c^{4}}{n^{4} k^{4}}\left(\frac{3}{20}-\frac{2 c}{15 n k}\right)+\ldots \\
& =\left[\frac{c^{2}}{6 n^{2} k^{2}}\left(1-\frac{c}{n k}\right)-\frac{c^{4}}{60 n^{4} k^{4}}\left(9-\frac{8 c}{n k}\right)+\ldots\right]>0
\end{aligned}
$$

According to (A.1) and (A.2), we have

$$
\hat{\theta}_{\mathrm{QEBS} 1}-\hat{\theta}_{\mathrm{QEBS} 2}=\hat{\theta}_{\mathrm{QEBBS} 3}-\hat{\theta}_{\mathrm{QEBS} 1}>0
$$

That is $\hat{\theta}_{\mathrm{QEBS} 2}<\hat{\theta}_{\mathrm{QEBS} 1}<\hat{\theta}_{\mathrm{QEBS} 3}$

ii) From (A.1) and (A.2), we get

$$
\begin{aligned}
& \lim _{n k \rightarrow \infty}\left(\hat{\theta}_{\text {QEBS1 }}-\hat{\theta}_{\text {OEBS2 }}\right)=\lim _{n k \rightarrow \infty}\left(\hat{\theta}_{\text {QEBS3 }}-\hat{\theta}_{\text {OEBS1 }}\right) \\
& =\left(\frac{\mathrm{w}+1}{\mathrm{c}}\right) \lim _{\mathrm{n} k \rightarrow \infty}\left[\frac{\mathrm{c}^{2}}{6 \mathrm{n}^{2} \mathrm{k}^{2}}\left(1-\frac{\mathrm{c}}{\mathrm{nk}}\right)-\frac{\mathrm{c}^{4}}{60 \mathrm{n}^{4} \mathrm{k}^{4}}\left(9-\frac{8 \mathrm{c}}{\mathrm{nk}}\right)+\ldots\right]=0
\end{aligned}
$$

That is $\lim _{\mathrm{n} k \rightarrow \infty} \hat{\theta}_{\mathrm{QEBS} 1}=\lim _{\mathrm{n} k \rightarrow \infty} \hat{\theta}_{\mathrm{QEBS} 2}=\lim _{\mathrm{n} k \rightarrow \infty} \hat{\theta}_{\mathrm{QEBS} 3}$

Thus, the proof is complete.

\section{Proof of Lemma 2}

i) From (3-9), (3-10) and (3-11), we get $\hat{\theta}_{\mathrm{QEBP} 1}-\hat{\theta}_{\mathrm{QEBP} 2}=\hat{\theta}_{\mathrm{QEBP} 3}-\hat{\theta}_{\mathrm{QEBP} 1}$

$$
=\left(\frac{\sqrt{(\mathrm{w}+1)(\mathrm{w}+2)}}{\mathrm{c}}\right)\left[\left(1+\frac{2 \mathrm{nk}}{\mathrm{c}}\right) \ln \left(1+\frac{\mathrm{c}}{\mathrm{nk}}\right)-2\right]
$$

According to (A.2) and (A.4), we have

$$
\hat{\theta}_{\mathrm{QEBP} 1}-\hat{\theta}_{\mathrm{QEBP} 2}=\hat{\theta}_{\mathrm{QEBP} 3}-\hat{\theta}_{\mathrm{QEBP} 1}>0
$$

That is $\hat{\theta}_{\mathrm{QEBP} 2}<\hat{\theta}_{\mathrm{QEBP} 1}<\hat{\theta}_{\mathrm{QEBP} 3}$

ii) From (A.3) and (A.4), we get

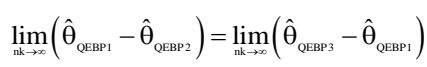

$=\left(\frac{\sqrt{(w+1)(w+2)}}{c}\right) \lim _{\mathrm{k} \rightarrow \infty}\left[\begin{array}{l}\frac{c^{2}}{6 n^{2} k^{2}}\left(1-\frac{c}{n k}\right)- \\ \frac{c^{4}}{60 n^{4} k^{4}}\left(9-\frac{8 c}{n k}\right)+\ldots\end{array}\right]=0$

That is $\lim _{\mathrm{n} k \rightarrow \infty} \hat{\theta}_{\mathrm{QEBP} 1}=\lim _{\mathrm{n} k \rightarrow \infty} \hat{\theta}_{\mathrm{QEBP} 2}=\lim _{\mathrm{n} k \rightarrow \infty} \hat{\theta}_{\mathrm{QEBP} 3}$

Thus, the proof is complete.

\section{Proof of Lemma 3}

i) From (3-12), (3-13) and (3-14), we obtain

$\hat{\theta}_{\mathrm{QEBE} 1}-\hat{\theta}_{\mathrm{QEBE} 2}=\hat{\theta}_{\mathrm{QEBE} 3}-\hat{\theta}_{\mathrm{QEBE} 1}=\left(\frac{\mathrm{w}}{\mathrm{c}}\right)\left[\left(1+\frac{2 \mathrm{nk}}{\mathrm{c}}\right) \ln \left(1+\frac{\mathrm{c}}{\mathrm{nk}}\right)-2\right]$

According to (A.2) and (A.6), we have

$\hat{\theta}_{\mathrm{QEBEI}}-\hat{\theta}_{\mathrm{QEBE} 2}=\hat{\theta}_{\mathrm{QEBE} 3}-\hat{\theta}_{\mathrm{QEBE} 1}>0$

That is $\hat{\theta}_{\mathrm{QEBE} 2}<\hat{\theta}_{\mathrm{QEBE} 1}<\hat{\theta}_{\mathrm{QEBE} 3}$

ii) From (A.3) and (A.6), we get

$\lim _{\mathrm{n} k \rightarrow \infty}\left(\hat{\theta}_{\mathrm{QEBP} 1}-\hat{\theta}_{\mathrm{QEBP} 2}\right)=\lim _{\mathrm{n} k \rightarrow \infty}\left(\hat{\theta}_{\mathrm{QEBP} 3}-\hat{\theta}_{\mathrm{QEBP} 1}\right)$

$$
=\left(\frac{w}{c}\right) \lim _{n k \rightarrow \infty}\left[\frac{c^{2}}{6 n^{2} k^{2}}\left(1-\frac{c}{n k}\right)-\frac{c^{4}}{60 n^{4} k^{4}}\left(9-\frac{8 c}{n k}\right)+\ldots\right]=0
$$

That is $\lim _{n k \rightarrow \infty} \hat{\theta}_{\text {QEBE1 }}=\lim _{n k \rightarrow \infty} \hat{\theta}_{\text {QEBE2 }}=\lim _{n k \rightarrow \infty} \hat{\theta}_{\text {QEBE3 }}$

Thus, the proof is complete.

\section{Proof of Lemma 4}

i) From (3-15), (3-16) and (3-17) that

$$
\begin{aligned}
\hat{\theta}_{\text {QевBD }}-\hat{\theta}_{\text {QевD2 }} & =\hat{\theta}_{\text {РЕвD }}-\hat{\theta}_{\text {QевD1 }} \\
& =\left(\frac{2(\mathrm{w}+2)}{\mathrm{c}}\right)\left[\left(1+\frac{2 \mathrm{nk}}{\mathrm{c}}\right) \ln \left(1+\frac{\mathrm{c}}{\mathrm{nk}}\right)-2\right]
\end{aligned}
$$

According to (A.2) and (A.8), we have

$$
\hat{\theta}_{\text {QEBD1 }}-\hat{\theta}_{\text {QEBD2 }}=\hat{\theta}_{\text {QEBD3 }}-\hat{\theta}_{\text {QEBD1 }}>0
$$

That is $\hat{\theta}_{\text {QевD2 }}<\hat{\theta}_{\text {РевD1 }}<\hat{\theta}_{\text {QевB3 }}$

ii) From (A.3) and (A.8), we get

$\lim _{\mathrm{n} k \rightarrow \infty}\left(\hat{\theta}_{\text {QEBD1 }}-\hat{\theta}_{\text {QEBD2 }}\right)=\lim _{\mathrm{n} k \rightarrow \infty}\left(\hat{\theta}_{\text {QEBD3 }}-\hat{\theta}_{\text {QEBD1 }}\right)$

$$
=\left(\frac{2(w+2)}{c}\right) \lim _{n k \rightarrow \infty}\left[\frac{c^{2}}{6 n^{2} k^{2}}\left(1-\frac{c}{n k}\right)-\frac{c^{4}}{60 n^{4} k^{4}}\left(9-\frac{8 c}{n k}\right)+\ldots\right]=0
$$

That is $\lim _{n k \rightarrow \infty} \hat{\theta}_{\text {QEBD1 }}=\lim _{n k \rightarrow \infty} \hat{\theta}_{\text {QEBD2 } 2}=\lim _{n k \rightarrow \infty} \hat{\theta}_{\text {QEBD3 }}$

Thus, the proof is complete.

Proof of Lemma 5

i) From (3-18), (3-19) and (3-20) that

$$
\begin{aligned}
& \hat{\theta}_{\text {QевQ1 }}-\hat{\theta}_{\text {РвBQ2 }}=\hat{\theta}_{\text {QвBQ3 }}-\hat{\theta}_{\text {РевQ1 }} \\
& =\left(\frac{2(\mathrm{w}-1)}{\mathrm{c}}\right)\left[\left(1+\frac{2 \mathrm{nk}}{\mathrm{c}}\right) \ln \left(1+\frac{\mathrm{c}}{\mathrm{nk}}\right)-2\right]
\end{aligned}
$$


According to (A.2) and (A.10), we have

$\hat{\theta}_{\text {QЕвQ1 }}-\hat{\theta}_{\text {СЕвQ2 }}=\hat{\theta}_{\text {QЕвQ3 }}-\hat{\theta}_{\text {QЕвQ1 }}>0$

That is $\hat{\theta}_{\text {РЕве2 }}<\hat{\theta}_{\text {QввQ1 }}<\hat{\theta}_{\text {РввQ3 }}$

ii) From (A.3) and (A.10), we get

$\lim _{n k \rightarrow \infty}\left(\hat{\theta}_{\text {QЕBQ1 }}-\hat{\theta}_{\text {QвBQ2 }}\right)=\lim _{\mathrm{nk} \rightarrow \infty}\left(\hat{\theta}_{\text {QEBQ3 }}-\hat{\theta}_{\text {QEBQ1 }}\right)$

$=\left(\frac{2(w-1)}{c}\right) \lim _{n \rightarrow \rightarrow \infty}\left[\frac{c^{2}}{6 n^{2} k^{2}}\left(1-\frac{c}{n k}\right)-\frac{c^{4}}{60 n^{4} k^{4}}\left(9-\frac{8 c}{n k}\right)+\ldots\right]=0$

That is $\lim _{\mathrm{n} k \rightarrow \infty} \hat{\theta}_{\text {QЕBQ1 }}=\lim _{\mathrm{n} \rightarrow \rightarrow \infty} \hat{\theta}_{\text {QЕBQ2 }}=\lim _{\mathrm{n} k \rightarrow \infty} \hat{\theta}_{\text {QЕВQ3 }}$

Thus, the proof is complete.

\section{Appendix (2)}

\section{Proof of Lemma 6}

Since $a, \frac{1}{(a+n k)^{w+2}}$ are continuous on $(0, c)$, according to the extended case of mean value theorem for definite integrals (when $0<\mathrm{a}<\mathrm{c})$, there is as least one number $\mathrm{a}_{1} \in(0, \mathrm{c})$ such that

$$
\int_{0}^{c} \frac{a d a}{(a+n k)^{w+2}}=\frac{1}{\left(a_{1}+n k\right)^{w+2}} \int_{0}^{c} a d a=\frac{c^{2}}{2\left(a_{1}+n k\right)^{w+2}}
$$

Similarly, there is as least one number $a_{2} \in(0, c)$ such that

$\int_{0}^{c} \frac{a d a}{(a+n k)^{w+1}}=\frac{1}{\left(a_{2}+n k\right)^{w+1}} \int_{0}^{c} a d a=\frac{c^{2}}{2\left(a_{2}+n k\right)^{w+1}}$

By substitution from (A.12) and (A.13) in (4-8), we get

$$
\begin{aligned}
& \hat{\theta}_{\text {OHBSI }}=\left(\frac{w+1}{a_{1}+n k}\right)\left[\frac{a_{2}+n k}{a_{1}+n k}\right]^{w+1} \\
& \therefore \lim _{\mathrm{nk} \rightarrow \infty} \hat{\theta}_{\text {QHBSL }}=\lim _{\mathrm{nk} \rightarrow \infty}\left(\frac{\mathrm{w}+1}{\mathrm{a}_{1}+\mathrm{nk}}\right)\left[\frac{\mathrm{a}_{2}+\mathrm{nk}}{\mathrm{a}_{1}+\mathrm{nk}}\right]^{\mathrm{w}+1} \\
& =(w+1) \lim _{n k \rightarrow \infty}\left\{\left(\frac{1}{a_{1}+n k}\right)\left[\frac{a_{2}+n k}{a_{1}+n k}\right]^{w+1}\right\}=0
\end{aligned}
$$

According to (A.3) and (A.14), we can deduct that

$$
\hat{\theta}_{\text {QЕBSI }}=\hat{\theta}_{\text {онBSI }}
$$

Also $\mathrm{a}^{2}, \frac{1}{(\mathrm{a}+\mathrm{nk})^{\mathrm{w}+2}}$ are continuous on $(0, \mathrm{c})$, according to the extended case of mean value theorem for definite integrals (when $0<\mathrm{a}<\mathrm{c})$, there is as least one number $\mathrm{a}_{1} \in(0, \mathrm{c})$ such that

$$
\int_{0}^{c} \frac{a^{2} d a}{(a+n k)^{w+2}}=\frac{1}{\left(a_{1}+n k\right)^{w+2}} \int_{0}^{c} a^{2} d a=\frac{3 c^{2}}{3\left(a_{1}+n k\right)^{w+2}}
$$

Similarly, there is as least one number $a_{2} \in(0, c)$ such that

$$
\int_{0}^{c} \frac{a^{2} d a}{(a+n k)^{w+1}}=\frac{1}{\left(a_{2}+n k\right)^{w+1}} \int_{0}^{c} a^{2} d a=\frac{c^{2}}{3\left(a_{2}+n k\right)^{w+1}}
$$

By substitution from (A.15) and (A.16) in (4-9), we get $\hat{\theta}_{\text {QHBS2 }}=\left(\frac{w+1}{a_{1}+n k}\right)\left[\frac{a_{2}+n k}{a_{1}+n k}\right]^{w+1}$

From (A.14)

$$
\therefore \lim _{\mathrm{n} \rightarrow \infty} \hat{\theta}_{\text {QHBs } 2}=0
$$

According to (A.3) and (A.17), we can deduct that

$$
\hat{\theta}_{\text {QEBS2 }}=\hat{\theta}_{\text {OHBS2 }}
$$

Furthermore, $a(c-a), \frac{1}{(a+n k)^{w+2}}$ are continuous on $(0, c)$, according to the extended case of mean value theorem for definite integrals [when $0<\mathrm{a}<\mathrm{c}, \mathrm{a}(\mathrm{c}-\mathrm{a})>0$ ], there is as least one number $a_{1} \in(0, c)$ such that

$\int_{0}^{c} \frac{a(c-a) d a}{(a+n k)^{\omega+2}}=\frac{1}{\left(a_{1}+n k\right)^{w+2}} \int_{0}^{c} a(c-a) d a=\frac{c^{3}}{6\left(a_{1}+n k\right)^{w+2}}$

Similarly, there is as least one number $\mathrm{a}_{2} \in(0, \mathrm{c})$ such that

$$
\int_{0}^{c} \frac{a(c-a) d a}{(a+n k)^{w+1}}=\frac{1}{\left(a_{2}+n k\right)^{w+1}} \int_{0}^{c} a(c-a) d a=\frac{c^{3}}{6\left(a_{2}+n k\right)^{w+1}}
$$

By substitution from (A.18) and (A.19) in (4-10), we get

$$
\hat{\theta}_{\text {OHBS }}=\left(\frac{\mathrm{w}+1}{\mathrm{a}_{1}+\mathrm{nk}}\right)\left[\frac{\mathrm{a}_{2}+\mathrm{nk}}{\mathrm{a}_{1}+\mathrm{nk}}\right]^{\mathrm{w}+1}
$$

From (A.14)

$$
\therefore \lim _{\mathrm{n} \rightarrow \infty} \hat{\theta}_{\text {QнBs } 3}=0
$$

According to (A.3) and (A.20), we can deduct that

$$
\hat{\theta}_{\text {Qевв3 }}=\hat{\theta}_{\text {онвS3 }}
$$

Thus, the proof is complete

\section{Proof of Lemma 7}

By using similar steps in lemma (6), we can get

$$
\int_{0}^{c} \frac{a d a}{(a+n k)^{w+3}}=\frac{1}{\left(a_{1}+n k\right)^{w+3}} \int_{0}^{c} a d a=\frac{c^{2}}{2\left(a_{1}+n k\right)^{w+3}}
$$

By substitution from (A.13) and (A.21) in (4-12), we get

$$
\begin{aligned}
& \hat{\theta}_{\text {OнBP1 }}=\sqrt{\left(\frac{(w+1)(w+2)}{\left(a_{1}+n k\right)^{2}}\right)\left[\frac{a_{2}+n k}{a_{1}+n k}\right]^{w+1}} \\
& \therefore \lim _{n k \rightarrow \infty} \hat{\theta}_{\text {OHBP1 }}=\lim _{n k \rightarrow \infty} \sqrt{\left(\frac{(w+1)(w+2)}{\left(a_{1}+n k\right)^{2}}\right)\left[\frac{a_{2}+n k}{a_{1}+n k}\right]^{w+1}} \\
& =\sqrt{(w+1)(w+2)} \lim _{n k \rightarrow \infty} \sqrt{\left(\frac{1}{a_{1}+n k}\right)^{2}\left[\frac{a_{2}+n k}{a_{1}+n k}\right]^{w+1}}=0
\end{aligned}
$$

According to (A.3) and (A.22), we can deduct that

$$
\hat{\theta}_{\mathrm{QEBP} 1}=\hat{\theta}_{\text {QHBPI }}
$$

Similarly, we can obtain 
$\hat{\theta}_{\mathrm{QEBPi}}=\hat{\theta}_{\mathrm{QHBPi}}(\mathrm{i}=2,3)$

Thus, the proof is complete.

\section{Proof of Lemma 8}

By using similar steps in lemma (6), we can get

$$
\begin{aligned}
& \int_{0}^{c} \frac{a d a}{(a+n k)^{w+1}}=\frac{1}{\left(a_{1}+n k\right)^{w+1}} \int_{0}^{c} a d a=\frac{c^{2}}{2\left(a_{1}+n k\right)^{w+1}}, \\
& \int_{0}^{c} \frac{a d a}{(a+n k)^{w}}=\frac{1}{\left(a_{1}+n k\right)^{w}} \int_{0}^{c} a d a=\frac{c^{2}}{2\left(a_{1}+n k\right)^{w}}
\end{aligned}
$$

By substitution from (A.23) and (A.24) in (4-16), we get

$$
\begin{aligned}
& \hat{\theta}_{\text {онвЕ। }}=\left(\frac{\mathrm{w}}{\mathrm{a}_{1}+\mathrm{nk}}\right)\left[\frac{\mathrm{a}_{2}+\mathrm{nk}}{\mathrm{a}_{1}+\mathrm{nk}}\right]^{\mathrm{w}+1} \\
& \therefore \lim _{n k \rightarrow \infty} \hat{\theta}_{\text {ОНвЕІ }}=\lim _{n k \rightarrow \infty}\left(\frac{\mathrm{w}}{a_{1}+n k}\right)\left[\frac{a_{2}+n k}{a_{1}+n k}\right]^{w+1} \\
& =w \lim _{n k \rightarrow \infty}\left\{\left(\frac{1}{a_{1}+n k}\right)\left[\frac{a_{2}+n k}{a_{1}+n k}\right]^{w+1}\right\}=0
\end{aligned}
$$

According to (A.3) and (A.25), we can deduct that

$$
\hat{\theta}_{\text {QEBEI }}=\hat{\theta}_{\text {QHBEI }}
$$

Similarly, we can obtain

$$
\hat{\theta}_{\text {QЕвEi }}=\hat{\theta}_{\text {QHBEi }}(\mathrm{i}=2,3)
$$

Thus, the proof is complete

\section{Proof of Lemma 9}

By using similar steps in lemma (6), we can get

$$
\int_{0}^{c} \frac{a d a}{(a+n k)^{w+3}}=\frac{1}{\left(a_{1}+n k\right)^{w+3}} \int_{0}^{c} a d a=\frac{c^{2}}{2\left(a_{1}+n k\right)^{w+3}}
$$

By substitution from (A.12) and (A.26) in (4-20), we get

$$
\begin{aligned}
& \hat{\theta}_{\text {OнBD1 }}=\left(\frac{\mathrm{w}+2}{a_{1}+n k}\right)\left[\frac{a_{2}+n k}{a_{1}+n k}\right]^{w+1} \\
& \therefore \lim _{n k \rightarrow \infty} \hat{\theta}_{\text {QHBD1 }}=\lim _{n k \rightarrow \infty}\left(\frac{w+2}{a_{1}+n k}\right)\left[\frac{a_{2}+n k}{a_{1}+n k}\right]^{w+1} \\
& =(w+2) \lim _{n k \rightarrow \infty}\left\{\left(\frac{1}{a_{1}+n k}\right)\left[\frac{a_{2}+n k}{a_{1}+n k}\right]^{w+1}\right\}=0
\end{aligned}
$$

According to (A.3) and (A.27), we can deduct that

$$
\hat{\theta}_{\text {QEBD } 1}=\hat{\theta}_{\text {QHBD1 }}
$$

Similarly, we can obtain

$$
\hat{\theta}_{\text {QEBDi }}=\hat{\theta}_{\text {QHBDi }}(\mathrm{i}=2,3)
$$

Thus, the proof is complete.

\section{Proof of Lemma 10}

By using similar steps in lemma (6), we can get

$$
\int_{0}^{c} \frac{a d a}{(a+n k)^{w-1}}=\frac{1}{\left(a_{1}+n k\right)^{w-1}} \int_{0}^{c} a d a=\frac{c^{2}}{2\left(a_{1}+n k\right)^{w-1}}
$$

By substitution from (A.24) and (A.27) in (4-24), we get

$$
\begin{aligned}
& \hat{\theta}_{\text {онве } 1}=\left(\frac{\mathrm{w}-1}{\mathrm{a}_{1}+\mathrm{nk}}\right)\left[\frac{\mathrm{a}_{2}+\mathrm{nk}}{\mathrm{a}_{1}+\mathrm{nk}}\right]^{\mathrm{w}+1} \\
& \therefore \lim _{\mathrm{nk} \rightarrow \infty} \hat{\theta}_{\text {Онве1 }}=\lim _{\mathrm{nk} \rightarrow \infty}\left(\frac{\mathrm{w}-1}{\mathrm{a}_{1}+\mathrm{nk}}\right)\left[\frac{\mathrm{a}_{2}+\mathrm{nk}}{\mathrm{a}_{1}+\mathrm{nk}}\right]^{\mathrm{w}+1}
\end{aligned}
$$

$$
=(w-1) \lim _{n k \rightarrow \infty}\left\{\left(\frac{1}{a_{1}+n k}\right)\left[\frac{a_{2}+n k}{a_{1}+n k}\right]^{w+1}\right\}=0
$$

According to (A.3) and (A.28), we can deduct that

$\hat{\theta}_{\mathrm{QEBQ1}}=\hat{\theta}_{\text {QHBQ1 }}$

Similarly, we can obtain

$\hat{\theta}_{\text {QЕвQi }}=\hat{\theta}_{\text {QHBQi }}(i=2,3)$

Thus, the proof is complete.

\section{References}

[1] A. K. Erlang, The theory of probabilities and telephone conversations. Nyt Tidsskrift for Matematik B 20, 6 (1909)87-98.

[2] K. Harischandra, S. S. Rao, A note on statistical inference about the traffic intensity parameter in $\mathrm{M} / \mathrm{Ek} / 1$ queue. Sankhya B, 50, (1988)144-148.

[3] S. K. Bhattacharyya, N. K. Singh, Intensity in M/Ek/1 queue. Far. East, Journal of Math and Science.2, 57 (1994) 57-62.

[4] Y. Fang, Hyper-Erlang distribution model and its application in wireless mobile networks. Wireless Networks, 7(2001)211-219. http://dx.doi.org/10.1023/A:1016617904269.

[5] Y. H. AbdelKader, Computing the moments of order statistics from nonidentically distributed Erlang variables. Statistical Papers, 45(2003)563-570. http://dx.doi.org/10.1007/BF02760568.

[6] P. k. Suri, B. Bhushan, A. Jolly, Time estimation for project management life cycles: A simulation approach, International Journal of Computer Science and Network Security, 9, 5(2009)211-215.

[7] A. Haq, S. dey, Bayesian estimation of Erlang distribution under different prior distributions, Journal of Reliability and Statistical Studies, 4, 1 (2011)1-30.

[8] R. A. Bakoban, Bayesian and non-Bayesian estimation of Erlang distribution under progressive censoring, IJRRAS, 11, 3 (2012)524535.

[9] A. H. Khan, T. R. Jan, Bayesian Estimation of Erlang Distribution under Different Generalized Truncated Distributions as Priors, Journal of Modern Applied Statistical Methods, 11, 2 (2012)416442.

[10] R. W. M. Wedderbuem, Quasi-Likelihood Functions, Generalized Models and the Gauss-Newton Method, Biometrika, 61, 3 (1974) 439-443.

[11] M. Han, Expected Bayesian Method for Forecast of Security Investment, Journal of Operations Research and Management Science 14,5 (2005) 89-102.

[12] M. Han, E-Bayesian Method to Estimate Failure Rate, The Sixth International Symposium on Operations Research and Its Applications (ISOR06) Xinjiang (2006)299-311.

[13] Q. Yin, H. Liu, Bayesian estimation of geometric distribution parameter under scaled squared error loss function, Conference on Environmental Science and Information Application Technology (2010)650-653.

[14] J. Wei, B. Song, W. Yan, Z. Mao, Reliability Estimations of BurrXII Distribution under Entropy Loss Function, IEEE (2011) 244 247. http://dx.doi.org/10.1109/icrms.2011.5979276.

[15] Z. F. Jaheen, H. M. Okasha, E-Bayesian Estimation for the Burr type XII model based on type- 2 censoring, Applied Mathematical 
$\begin{array}{llllll}\text { Modelling } & 35 & \text { (2011) } & 4730 & - & 4737 .\end{array}$ http://dx.doi.org/10.1016/j.apm.2011.03.055.

[16] G. Cai, W. Xu, W. Zhang, P. Wang, Application of E-Bayes method in stock forecast, Fourth International Conference on Information and Computing (2011)504-506 http://dx.doi.org/10.1109/icic.2011.40.

[17] H. M. Okasha, E-Bayesian estimation of system reliability with Weibull distribution of components based on type-2 censoring, Journal of Advanced Research in Scientific Computing 4, 4 (2012)34-45.

[18] X. Wu, E-Bayesian Estimation of Failure Probability under Zerofailure Data with Double Hyper Parameters, Journal of Applied Mechanics and Materials 190-191 (2012) 977-981. http://dx.doi.org/10.4028/www.scientific.net/AMM.190-191.977.

[19] R. Azimi, F, Yaghamei, B. Fasihi, E-Bayesian estimation based on generalized half Logistic progressive type-II censored data, International Journal of Advanced Mathematical Science 1, 2 (2013) 56-63.

[20] N. Javadkani, P. Azhdari, R. Azimi, On Bayesian estimation from two parameter Bathtub-shaped lifetime distribution based on progressive first-failure-censored sampling, International Journal of Scientific World $2, \quad 1 \quad$ (2014) 31-41 http://dx.doi.org/10.14419/ijsw.v2i1.2513.

[21] H. Liu, T. Yin, C. Wang, E-Bayes Estimation of Rayleigh Distribution Parameter, Journal of Applied Mechanics and Materials 596 (2014) 305-308 http://dx.doi.org/10.4028/www.scientific.net/AMM.596.305.

[22] H. M. Okasha, E-Bayesian Estimation for the Lomax distribution based on type-II censored data, Journal of the Egyptian Mathematical Society 22, 3 (2014) 489-495. http://dx.doi.org/10.1016/j.joems.2013.12.009.

[23] H. M. Reyad, S. O. Ahmed, E-Bayesian analysis of the Gumbel type-ii distribution under type-ii censored scheme, International Journal of Advanced Mathematical Sciences 3, 2 (2015) 108-120. http://dx.doi.org/10.14419/ijams.v3i2.5093.

[24] H. M. Reyad, S. O. Ahmed, Bayesian and E-Bayesian estimation for the Kumaraswamy distribution based on type-ii censoring. International Journal of Advanced Mathematical Sciences, 4, 1 (2016):10-17. http://dx.doi.org/10.14419/ijams.v4i1.5750.

[25] Reyad, H. M, Younis, A, M,. Alkhedir, A. A.(2016). Comparison of Estimates using Censored Samples from Gompertz Model: Bayesian, EBayesian, Hierarchical Bayesian and Empirical Bayesian Schemes. International Journal of Advanced Statistics and Probability 4, 1(2016):47$61 \mathrm{http} / / / \mathrm{dx}$. doi.org/10.14419/ijasp.v4i1.5914.

[26] A. Mood, F. A. Graybill, D. Boes, Introduction to the Theory of Statistics. McGraw-Hill Series in Probability and Statistics, 1974

[27] J. G. Nostrom, The use of precautionary loss function in risk analysis, IEEE Transaction on Reliability, 45, 3(1996)400-403.

[28] D. K. Dey, M. Gosh, C. Srinivasan, Simultaneous estimation of parameter under entropy loss, Journal of Statistical Planning and Inference (1987) 347-363.

[29] M. h. Degroot, Optimal Statistical Decision, McGraw-Hill Inc. (1970).

[30] M. K. Bhuiyan, M. K. Roy, M. F. Iman, Minimax estimation of the parameter of Rayleigh distribution, (2007) 207-212.

[31] M. Han, The structure of hierarchical prior distribution and its applications, Chinese Operations Research and Management Science 6, 3 (1997) 31-40.

[32] D. V. Lindley, A. F. Smith, Bayes estimation for the linear model, Journal of Royal Statistical Society B, 34 (1972)1-41.

[33] O. Shojaee, R. Azimi, M. Babanezhad, Empirical Bayes Estimators of Parameter and Reliability Function for Compound Rayleigh Distribution under Record Data, American Journal of Theoretical and Applied Statistics, $\quad 1, \quad$ (2012) 12-15. http://dx.doi.org/10.11648/j.ajtas.20120101.12. 